\title{
Conditional truth and future reference
}

\author{
Stefan Kaufmann* \\ Northwestern University \\ kaufmann@northwestern.edu
}

\begin{abstract}
This paper proposes a compositional model-theoretic account of the way the interpretation of indicative conditionals is determined and constrained by the temporal and modal expressions in their constituents.
\end{abstract}

\section{Introduction}

Two topics in the study of semantics which have recently received much renewed attention are conditionals and expressions of modality on the one hand, and tense and temporal reference, on the other. Each of them has its own history of increasingly sophisticated formal theories. Curiously, however, despite the wide currency of early accounts of the interaction between modal and temporal elements in the semantics of certain expressions (e.g., Dowty, 1977, 1979), most subsequent work in these areas addressed only one at the exclusion of the other. The standard approaches to conditionals and modality in the Eighties and Nineties dealt with sets of worlds and quantification over them, often paying little attention to the temporal and aspectual properties of the sentences involved. Likewise, theories of tense and aspect typically dealt with one world at a time, abstracting away from the modal nuances arising with differences between, for instance, past and future reference.

${ }^{*}$ I am grateful above all to Cleo Condoravdi, two anonymous reviewers, the audiences at CLS 38, the 2002 Stanford Workshop on Mood and Modality and the 2003 ESSLLI Workshop on Conditional and Unconditional Modality, for comments on earlier versions of this paper which led to great improvements. All remaining errors are my own. Part of this work was supported by the Japan Society for the Promotion of Science (JSPS, Grant \#P01063). 
While there are doubtless advantages to such a modular approach, there is also no question that the ultimate goal of developing a comprehensive semantic treatment of modality and temporality will require more than putting together one theory of each. Recent work on the ways in which they interact and constrain each other has brought back into focus the importance of keeping each in view when analyzing the other (Condoravdi, 2002; Fernando, 2003; Ippolito, 2003; Kaufmann, 2005, among others). The present paper contributes to this line of research. I propose an analysis of the temporal and modal properties of simple sentences and indicative conditionals, which accounts for the variety of readings observed in the latter in terms of the interplay between these dimensions. I will only be concerned with indicative conditionals, ignoring the separate problem of the morphological makeup of counterfactuals. In the remainder of this introduction, I will take a first look at the relevant data.

The class of conditionals that is often treated uniformly as "indicatives" is not as homogeneous as the label would suggest. Pairs like (1a,b) illustrate a distinction that has been the subject of a long-standing controversy.

a. If he submits his paper to a journal, we won't include it in our book.

b. If he submitted his paper to a journal, we won't include it in our book.

Two questions are of central importance in this debate. First, assuming that conditionals are built up compositionally from the connective 'if' and the two constituents, what are the expressions that form the input to this operation, especially the one that becomes the antecedent of the conditional, and how does the composition proceed? Second, how should the semantic difference between conditionals like $(1 \mathrm{a}, \mathrm{b})$ be characterized?

Regarding the first question, I will argue in this paper that the antecedents of (1a) and (1b) are literally (2a) and (2b), respectively. ${ }^{1}$

(2) a. He submits his paper to a journal.

b. He submitted his paper to a journal.

This claim, trivial though it may seem, has often been denied on the grounds that the antecedent of (1a), unlike that of (1b), does not appear to have the same interpretation in the conditional as it does in isolation: (2a) is only felicitous under a special reading which includes an element of "certainty"

\footnotetext{
${ }^{1}$ Some speakers, including an anonymous referee, find that (2b) requires the presence of a temporal adverbial like 'tomorrow'. Others believe that the future reference time may be supplied contextually (Steedman, 2002).
} 
or "scheduling" (Zandvoort, 1965; Lakoff, 1971; Vetter, 1973; Goodman, 1973; Wekker, 1976; Dowty, 1979; Quirk et al., 1985; Comrie, 1985). This connotation is absent in the antecedent of (1a). I will refer to it as the Certainty Condition (CC), leaving open until further discussion the question of its source and theoretical status. For now, what is important is that no similar contrast is felt between (1b) and (2b).

Some authors argue on the basis of such observations that the antecedent of (1a), unlike that of (1b), is not really a tensed clause (Dudman, 1984, 1989; Crouch, 1993). Others assume that the antecedent of (1a) is (3a) at some underlying level, and that the auxiliary 'will' is removed by a mechanism triggered by the 'if'-construction (McCawley, 1971; Comrie, 1985; Dancygier, 1998).

(3) a. He will submit his paper to a journal.

b. ?If he will submit his paper to a journal, we won't include it in the book.

This latter position is often accompanied by the claim that 'will' in the antecedent, as in (3b), results in ill-formedness unless it has a volitional reading, paraphraseable in this case as 'If he is willing to submit his paper...' (Palmer, 1974; Wekker, 1976; Dowty, 1979; Declerck and Reed, 2001).

I will show that none of the above assumptions are required for an adequate semantic account. Instead, I propose an anlysis that is strictly compositional, in the sense that the antecedents of all indicative conditionals receive exactly the same interpretation as they do in isolation. This proposal is uncontroversial for (1b), but the argument for extending it to (1a) requires a detailed analysis of the temporal and modal makeup of such sentences, as well as an answer to the second question, the one about the semantic difference between (1a) and (1b).

Regarding this question, I will argue that there is no significant difference between these sentences. This claim, too, is at odds with much of the literature, as it appears to fly in the face of rather solid intuitions to the contrary. While indicative conditionals are generally used under uncertainty about the truth value of the antecedent, the source and nature of this uncertainty are not the same in the two cases. Funk (1985, pp. 375-376) stated the difference lucidly:

In the case of [1a] the uncertainty is largely due to the fact that the state-of-affairs described and predicated does not yet exist, i.e., is still subject to manifestation (so that it cannot be affirmed or denied - it is unverifiable) at the moment of the sentence being 
uttered. In [1b], however, the state-of-affairs does exist at the time of speaking (either in the positive or negative sense - it is 'manifested' and could thus be verified), but the speaker has not got enough information (or is otherwise not disposed) to be sure about it and hence to affirm or deny it. Accordingly, the meaning of the conditioning frame can be said to vary from "if it happens that..." to "if it is true that..." (emphasis in the original)

Many authors have made similar remarks to the effect that in (1b), but not in (1a), the truth value of the antecedent is either known to someone other than the speaker, or knowable in principle, or in any case somehow "out there" (Close, 1980; Dancygier, 1998; Declerck and Reed, 2001; Garrett, 2001).

This distinction is real, and it constitutes an important part of the motivation for my proposal. However, I do not consider it a criterion for distinguishing between conditional sentences. Rather, it is readings of such sentences that fall in one class or the other. Consider the "scheduling" reading on which (2a) is felicitous. Notice that the antecedent of (1a) can have this reading ('If he is (now) scheduled to submit his paper...'), and that (1a) under this interpretation shares the property of "verifiability" of a state of affairs with (1b). Similarly, the antecedent of (1b), its Past tense notwithstanding, can refer to future states of affairs that are not yet "verifiable" at speech time ('If (it turns out in the future that) he submitted his paper...'). Under this "past-in-the-future" interpretation, the criterion would group it together with (1a). Natural contexts in which these readings become salient are given in $(4 a, b)$.

a. [We'll check what was decided about these manuscripts at yesterday's meeting.] If he submits his paper to a journal, we won't include it in our book.

b. [We'll contact potential contributors next month to see which of these manuscripts are still available then.] If he submitted his paper to a journal, we won't include it in our book.

Now, the existence of such readings is in itself not an argument against the use of Funk's criterion in classifying conditional sentences. We could say that (1a) and (4a) are distinct, homonymous conditionals, similarly for (1b) and (4b), and accordingly classify (1a) and (4b) together on one side, and (1b) and (4a) on the other. But we would then be dealing with four sentences instead of two, and there had better be good arguments for postulating such a cross-cutting taxonomy. 
I will show that on the contrary, there are good arguments against such a move, not the least of them being that a simpler analysis is possible, as I will demonstrate. Moreover, within this analysis, the intuitive difference alluded to by Funk and others falls out as a consequence of a semantic variation whose statement makes no reference to tenses or other structural properties of the sentences involved, nor to extralinguistic notions such as the status of states of affairs. Instead, the difference involves the relation between the speech time and the time at which the constituent clauses are evaluated. The semantic effects observed by Funk and others follow as a consequence of this difference, together with certain assumptions about the interaction of time and modality that are built into the model.

The details of this account have to wait until some formal preliminaries are in place. Throughout this paper, I will distinguish between predictive and non-predictive readings of conditionals. The former differ from the latter in that the antecedent (i) carries the Certainty Condition when used in isolation, but not in the conditional, and (ii) refers to a state of affairs that is not yet "manifest" or "verifiable" at speech time. I take (i) and (ii) to be reflections of the same semantic property.

Sections 2 and 3 set up the model-theoretic background and the framework of the compositional analysis. Sections 4,5 and 6 are respectively devoted to the bare tenses, the modal 'will', and the conditional. Section 7 surveys the motivations and predictions of the proposed theory with regard to a variety of additional data. Section 8 raises some questions for future work.

\section{Preliminaries}

The account is based on the standard analysis of conditionals, spelled out formally in terms of quantification over possible worlds. A sentence "if $A$ then $C$ ' asserts of a set of worlds $K$ that $C$ is true at all, most or few worlds in $K$ at which $A$ is true (depending on the modal involved). Authors differ in their assumptions as to whether $K$ represents the speaker's knowledge (Ramsey, 1929) or beliefs (Stalnaker, 1968), the common ground (Stalnaker, 1975) or some other conversational background (Kratzer, 1979, 1991). I will focus on two kinds of conversational backgrounds: objective and doxastic (or subjective) ones. This distinction has traditionally proven useful in the analysis of conditionals and has a central place in related areas as well; cf. Condoravdi's (2002) metaphysical/epistemic distinction in the treatment of modals in time. 
In addition to this quantificational semantic core, the account draws on the interaction of the two modalities with each other and with time. Time plays a central role inasmuch as many of the observations can be traced to the well-known asymmetry between a "fixed" past and present and an "open" future, discussed since Aristotle and incorporated in many tense logics, including the one I am going to use as a point of departure.

\section{$2.1 \quad$ Models}

The formal framework is based on a version of Thomason's (1970; 1984) " $T \times W$-frames."

\section{Definition $1(\mathrm{~T} \times \mathrm{W}$-frame-Thomason, 1984)}

$A T \times W$-frame is a structure $\langle W, T,<, \approx\rangle$, where $W$ and $T$ are disjoint nonempty sets; $<$ is a transitive relation on $T$ which is also irreflexive and linear; and $\approx$ is a relation in $T \times W \times W$ such that (i) for all $t \in T, \approx_{t}$ is an equivalence relation; (ii) for all $t, t^{\prime} \in T$ and $w, w^{\prime} \in W$, if $w \approx_{t} w^{\prime}$ and $t^{\prime}<t$ then $w \approx_{t^{\prime}} w^{\prime}$

I will spell out the proposal in terms of world-time pairs (Montagovian indices), and it will be convenient to extend the relations introduced in Definition 1 to this two-dimensional domain:

\section{Definition 2}

Given a $T \times W$-frame $\langle W, T,<, \approx\rangle$, let $I=W \times T$. The relations $<$ and $\approx$ are extended to $I \times I$ as follows:

a. $\langle w, t\rangle \approx\left\langle w^{\prime}, t^{\prime}\right\rangle$ if and only if $w \approx_{t} w^{\prime}$ and $t=t^{\prime}$;

b. $\langle w, t\rangle\left\langle\left\langle w^{\prime}, t^{\prime}\right\rangle\right.$ if and only if $w=w^{\prime}$ and $t<t^{\prime}$.

I will usually refer to world-time pairs in $I$ using the letters $i, j, \ldots$, and write ' $i \leq j$ ' for ' $i<j$ or $i=j$ '.

The $\approx$-relation represents objective indeterminacy. It identifies for each time $t$ those classes of worlds which are historical alternatives of each other at $t$. Definition 1 ensures that these historical alternatives form equivalence classes. Historical necessity - the notion that what has been cannot (now) have been otherwise, even though it could have been otherwise - is incorporated in Definition 3 as a condition on truth assignments. Only those assignments are admissible under this definition which respect the intuition that historical alternatives at $t$ are indistinguishable at all times up to and including $t$. 


\section{Definition 3 (History model)}

Let $\mathcal{A}$ be a set of propositional variables. $A$ history model for $\mathcal{A}$ is a structure $\mathcal{M}=\langle W, T,<, \approx, V\rangle$, where $\langle W, T,<, \approx\rangle$ is a $T \times W$-frame and $V: \mathcal{A} \mapsto$ $(I \mapsto\{0,1\})$ is a truth assignment for $\mathcal{A}$ such that for all $A \in \mathcal{A}$ and $i, j \in I$, if $i \approx j$ then $V(A)(i)=V(A)(j)$.

The relation $\approx$ has a special status in that the properties of other accessibility relations are defined in terms of their interaction with it. Definition 4 fixes some useful terminology.

\section{Definition 4 (Historicity and lack of foreknowledge)}

An accessibility relation $R$ in $I \times I$ is

a. modal if and only if $\langle w, t\rangle R\left\langle w^{\prime}, t^{\prime}\right\rangle$ implies $t=t^{\prime}$;

b. temporal if and only if $\langle w, t\rangle R\left\langle w^{\prime}, t^{\prime}\right\rangle$ implies $w=w^{\prime}$.

$A$ modal accessibility relation $R$

a. is historical if and only if $i R j$ and $i \approx k$ jointly imply $k R j$;

$b$. lacks foreknowledge if and only if $i R j$ and $j \approx k$ jointly imply $i R k$.

A historical accessibility relation is one which behaves like facts in that the set of worlds accessible through it at a given time must be constant across historical alternatives. A relation lacks foreknowledge if it does not "cut across" equivalence classes of historical alternatives; in other words, if it cannot foresee the future.

Speakers' belief states are modeled by accessibility relations that resemble $\approx$, but are subject to somewhat looser conditions to accommodate subjective uncertainty about the past. Whereas Definitions 1 and 3 jointly ensure that there is no objective uncertainty about the past, Definition 5 allows for an agent's doxastic state to be consistent with alternative pasts, each "filling in the blanks" in different ways.

\section{Definition 5 (Doxastic history)}

Given a history model $\langle W, T,<, \approx, V\rangle$, a doxastic history is a modal relation $\sim$ in $I \times I$ that is historical and lacks foreknowledge, and such that

a. $\sim$ is transitive, serial and euclidean $;^{2}$

b. if $i \sim j, i^{\prime}<i$ and $j^{\prime}<j$, then $i^{\prime} \sim j^{\prime}$.

According to Definition 5, the agent $a$ whose beliefs are traced through time by $\sim^{a}$ is a rather idealized one: The monotonicity condition imposed in (b), similar to that for $\approx$ in Definition 1 , implies that the only way to change

\footnotetext{
${ }^{2}$ Transitive: if $i \sim j$ and $j \sim k$ then $i \sim k$. Serial: For all $i$ there is a $j$ such that $i \sim j$. Euclidean: if $i \sim j$ and $i \sim k$ then $j \sim k$. See Fagin et al. (1995); Stalnaker (2002).
} 
one's beliefs is by eliminating links from the accessibility relation. Thus it is impossible for worlds to become accessible: The agent never forgets or revises previously held beliefs. A further limitation is that all indices that are doxastically accessible from $i$ must be cotemporal with $i$, which means in effect that the agent always knows what time it is. These restrictions are unrealistic, but they do no harm for my purposes in this paper. I will drop the diacritics from $\sim$ where no confusion can arise.

Notice that $\sim$ is not required to be reflexive. Adding this requirement would make it an equivalence relation, implying that all of the agent's beliefs are true. Such a relation could be properly called "epistemic." I leave this option open; nothing hinges on it here. Notice also that although doxastic relations evolve along the same temporal dimension as history itself, the order in which facts become known is decoupled from the order in which they materialize, subject only to the constraint that they cannot be known in advance.

Finally, I will have occasion to appeal to the fact that sentences are often implicitly relativized to various kinds of evidence or assumptions. For instance, (5a), besides making a claim about the actual departure time of the flight, could also state what the schedule says about that departure time. In the latter case, it is interpreted as implicitly prefixed with a reference to the timetable, as in (5b).

(5) a. The plane leaves at 4 PM.

b. [According to the timetable] the plane leaves at 4 PM.

I follow Kratzer in calling such bodies of information modal bases.

Definition 6 (Modal base)

A modal accessibility relation $R \subseteq I \times I$ is a modal base if and only if it is historical.

Notice that objective and doxastic relations are modal bases. Definition 6 ensures that modal bases in general are constant across historical alternatives, thus subject to historical necessity. What the timetable says about the departure time of tomorrow's plane is objectively fixed, like the actual departure time of yesterday's plane and unlike the actual departure time of tomorrow's. No other conditions are imposed, although more can be specified in particular cases as needed.

\section{$2.2 \quad$ Settledness}

The various accessibility relations introduced above give rise to different interpretations of "necessity." Consider for simplicity the language of proposi- 
tional logic, interpreted by a valuation function $V$ which respects the condition in Definition 3 above. Let this language be closed under the operators $\square_{R}$ for all accessibility relations $R$, interpreted as usual by universal quantification over the indices accessible via $R$ from the index of evaluation. (I will use a different syntax for these and related statements below, but in this section there is no need to depart from the familiar format.)

Necessity and possibility relative to temporal relations (e.g., $\square_{<}$and $\left.\diamond_{<}\right)$correspond to Priorian tense operators. More interesting is the case of modal accessibility relations. Historical alternatives, belief states and modal bases all come with their own necessity operators. ${ }^{3}$

Necessity with respect to historical alternatives was first studied by Prior (1967) and subsequently termed settledness (Thomason and Gupta, 1981; see also van Fraassen, 1981). Some consequences of the interaction between different accessibility relations and $\approx$ are worth mentioning here. The following is an immediate consequence of the reflexivity of $\approx$.

\section{Remark 1}

For any accessibility relation $R$ :

a. $\square \approx \square_{R} \varphi \Longrightarrow \square_{R} \varphi$;

b. $\square_{R} \square \approx \varphi \Longrightarrow \square_{R} \varphi$.

The conditions of historicity and lack of foreknowledge from Definition 4 translate into the following axioms:

\section{Remark 2}

An accessibility relation $R$

a. is historical if and only if $\square_{R} \varphi \Longrightarrow \square_{\approx} \square_{R} \varphi$;

b. lacks foreknowledge if and only if $\square_{R} \varphi \Longrightarrow \square_{R} \square \approx \varphi$.

In the doxastic case, (a) if an agent entertains a belief, it is settled that he does, and (b) to believe a sentence is to believe that it is settled. Only (a) is valid for modal bases in general.

The distinction between truth simpliciter and settledness allows us to identify an attitude towards propositions that lies between ignorance and belief: One may believe that the question of the truth or falsehood of a sentence is settled without knowing which way, i.e., without knowing whether it is true or false. I will refer to this attitude as the presumption of decidedness. $^{4}$

\footnotetext{
${ }^{3}$ The resulting logic depends on the properties of the accessibility relation; specifically, S5 for $\square \approx$ and $\mathrm{K} 45$ for $\square_{\sim}$.

${ }^{4}$ In Kaufmann (2002), I call this notion the "presumption of settledness." An anony-
} 


\section{Definition 7 (Presumption of decidedness)}

A sentence $\varphi$ is presumed decided by an agent $a$ at $i \in I$ if and only if $\square_{\sim^{a}}(\varphi \rightarrow \square \approx \varphi)$ is true at $i$.

I offer this notion as the formal analog of the "knowability" or "verifiability in principle" that has often been identified in the literature as the defining property of epistemic conditionals (cf. the quotation from Funk, 1985, in the introduction). Definition 7 and the conditions on $\approx$ and $\sim$ jointly imply that sentences whose truth value depends on facts no later than the time of evaluation are necessarily presumed decided in any admissible belief state, whereas sentences about the future may fail to be. Furthermore, by historicity, $\square_{R} \varphi$ is necessarily presumed decided for any modal base $R$.

\section{English}

Turning now to the compositional analysis of English sentences, I adopt certain common assumptions about the relative scope of the modal and temporal elements involved. It will be clear, however, that the functioning of the system does not hinge on these assumptions: Re-typing the elements and re-arranging the function application would require no more than a technical exercise.

Four elements of the proposal will in the end jointly determine the interpretation of conditionals: modal bases, modal forces, tenses, and, in some cases, ordering sources. All four are represented by distinct semantic objects which enter the derivation at different points. Before turning to that part of the account, I will introduce some basic ingredients.

\subsection{The setup}

Semantic interpretations are built up and represented in a typed language which I will not define in full detail; it contains variables ranging over indices as well as (characteristic functions of) sets thereof and relations between them, constants denoting the relations in the model, and the usual logical connectives. Both the language and its intended interpretation will become clear as we go along. I need two atomic types, $s$ for indices and $t$ for truth values, out of which functional types are built recursively in the familiar way. I will refer to characteristic functions of sets of indices (i.e., functions of type $\langle s, t\rangle)$ as "propositions," occasionally reminding the reader that they are not

mous reviewer found this term confusing, since the intention is that it is the question of 'whether $\varphi$ ' that is settled, not the proposition 'that $\varphi$ '. 
sets of worlds, but sets of world-time pairs. The advantage of working at this level will become evident below in dealing with predictive conditionals.

The smallest linguistic units in the analysis are sentence radicals. Linguistically, they are found roughly at the VP level (assuming a VP-internal subject). Intuitively, they may be thought of as saturated but tenseless and non-modalized event descriptions.

The ontological commitments of the analysis are minimal. I assume that a valuation function $V$ assigns truth values to sentence radicals at world-time pairs without distinguishing them aspectually, thus avoiding the question of what exactly it means for a sentence of a particular aspectual class to be true at a given time. Such conditions can be added as meaning postulates. Nor do I treat events and states as objects in their own right, as has been proposed, for instance, by Condoravdi (2002) and Portner (2003). A more comprehensive theory may well need such complexity, but the present account does not depend on it.

\subsection{Sentence radicals}

Sentence radicals are interpreted with respect to propositions (i.e., sets of indices). At this basic level, the evaluation involves existential quantification: A radical $R a d$ is true of a set of indices whenever it is true according to the valuation function $V$ at some member of this set. For reasons that will become clear in the discussion of temporal frame adverbials, it is useful to make the index of evaluation of the matrix clause available throughout the derivation. I will reserve the variables $s, s_{0}, s_{1}, \ldots$ (mnemonic for "speech index") for this purpose. In the definition schema in (6), $s$ is included for uniformity, but semantically vacuous. 'Rad' stands for sentence radicals, and $x$ is variable ranging over (characteristic functions of) sets of indices.

$$
\llbracket \operatorname{Rad} \rrbracket=\lambda x \lambda s . \exists k[x(k) \wedge V(\operatorname{Rad})(k)]
$$

Thus the denotations of sentence radicals are of type $\langle\langle s, t\rangle,\langle s, t\rangle\rangle$. As an example, the interpretation of the radical 'he arrive' is given in (7). The subscripts on $x_{0}$ and $s_{0}$ carry no special significance; they will be useful when the same example is subjected to further manipulations below, where additional variables $x_{1}, s_{1}, \ldots$ will be introduced for the sake of perspicuity.

$$
\llbracket \text { [he arrive } \rrbracket=\lambda x_{0} \lambda s_{0} . \exists k\left[x_{0}(k) \wedge V(\text { he arrive })(k)\right]
$$

In principle, this denotation may be applied to any arbitrary set of indices. As we will see, however, elements higher up in the derivation tree, such as tenses and modals, as well as the utterance time, conspire to delimit this 
region in various ways. In particular, the set of indices that actually gets passed to the radical level will always be a temporal interval (i.e., an uninterrupted sequence of indices with a constant world coordinate). Anticipating this result, I will call it the "reference interval."

\subsection{Frame adverbials}

Aside from tenses, temporal frame adverbials are the primary sentenceinternal sources of temporal restrictions on the reference interval. A thorough analysis of their semantic properties would lead far afield, but some comments on their treatment are in order.

To do at least some justice to the variety of frame adverbials, we should distinguish three major classes, which I will call (following Smith, 1991) referential (those containing proper names, such as 'on February 12, 2004'); deictic (those whose denotation depends on the speech time, such as 'tomorrow', 'now'); and (iii) anaphoric (those whose denotation depends on the local reference time in embedding contexts, such as 'then', 'the following day'). The examples I consider in this paper only contain adverbials of the second class. I give formal definitions for this class only; the treatment could be extended to the others, but doing so would distract from the main concerns of this paper.

Deictic frame adverbials are interpreted in terms of accessibility relations: 'Tomorrow' denotes a relation which holds between an index $i$ and all those indices which lie within the day following $i$. Anaphoric adverbials are interpreted similarly, but obtain their first argument from the reference time. Referential adverbials may be analyzed for uniformity in terms of a relation that is constant on its first argument.

In general, the denotations of frame adverbials cannot be defined in terms of temporal coordinates alone, but must be allowed to vary from world to world: The interval denoted by 'after dinner' depends on when 'dinner' is, which may itself be (subjectively or objectively) uncertain at evaluation time. Not all adverbials have this property - 'February 12, 2004' is a rigid designator, and the set of indices that are 'tomorrow' from the perspective of cotemporal indices does not vary across worlds — but for generality, I will assume that all adverb denotations depend on both coordinates, world and time, of their first argument.

For deictic adverbials like 'tomorrow', it must be ensured that the time coordinate of their first argument is the speech time. For simple sentences, this is not a problem because the speech time coincides with the evaluation time; in embedded contexts, however, such as the antecedents of certain 
conditionals, the speech time is the evaluation of the matrix clause, which may differ from that of the constituents. This is the reason why the speech time is made available throughout the derivation in the special variable $s$.

The most straightforward way to represent adverbial denotations as relations between indices is extensional: The denotion of 'tomorrow' relates an index $s=\langle w, t\rangle$ only with indices $\left\langle w, t^{\prime}\right\rangle$ with the same world coordinate, where $t^{\prime}$ lies in the relevant future (or past) interval. Such relations can be specified along the following lines:

$$
\text { tom }=\lambda\langle w, t\rangle \lambda\left\langle w, t^{\prime}\right\rangle\left[t^{\prime} \text { lies in the day following } t \text { at } w\right]
$$

However, as we will see, to deal with conditionals, we need an intensionalized version of this. In the interpretation of 'If he comes tomorrow...' at an index $s=\langle w, t\rangle$, the 'tomorrow'-relation must make accessible indices at alternative worlds which lie in the interval specified, at those worlds, as in (8) and relative to time $t$. The interpretation I will be using can be given in terms of (8) as in (9).

$$
\mathrm{TOM}=\lambda\langle w, t\rangle \lambda\left\langle w^{\prime}, t^{\prime}\right\rangle \cdot\left\langle w^{\prime}, t\right\rangle \operatorname{tom}\left\langle w^{\prime}, t^{\prime}\right\rangle
$$

The first argument of this denotation will generally be the speech index $s$. I will write ' $\operatorname{TOM}_{s}(i)$ ' for ' $\operatorname{TOM}(s)(i)$ ', the statement that $i$ is 'tomorrow', in the sense of (9), from the perspective of $s$. The denotations of adverbials are functions of type $\langle\langle\langle s, t\rangle,\langle s, t\rangle\rangle,\langle\langle s, t\rangle,\langle s, t\rangle\rangle\rangle$, that is, modifiers of sentence radicals, defined in the schema (10). ' $\varphi$ ' is a variable over sentence radicals; 'Adv' and 'ADV' stand for words like 'tomorrow' and denotations like TOM, respectively.

$$
\llbracket A d v \rrbracket=\lambda \varphi \lambda x \lambda s \cdot \varphi\left(\lambda j \cdot x(j) \wedge \operatorname{ADV}_{s}(j)\right)(s)
$$

Thus the semantic contribution of adverbials consists in restricting the reference interval to $\mathrm{ADV}_{s}$. As an example, the application of 'tomorrow' to (7) above, detailing every step of the simplification, is given in (11).

$$
\begin{aligned}
\llbracket & \text { tomorrow }(\text { he arrive }) \rrbracket \\
= & \lambda \varphi \lambda x_{1} \lambda s_{1} . \\
& {\left[\varphi\left(\lambda j \cdot x_{1}(j) \wedge \operatorname{TOM}_{s_{1}}(j)\right)\left(s_{1}\right)\right]\left(\lambda x_{0} \lambda s_{0} \cdot \exists k\left[x_{0}(k) \wedge V(\text { he arrive })(k)\right]\right) } \\
= & \lambda x_{1} \lambda s_{1} . \\
& {\left[\lambda x_{0} \lambda s_{0}\left[\exists k\left[x_{0}(k) \wedge V(\text { he arrive })(k)\right]\right]\left(\lambda j \cdot x_{1}(j) \wedge \operatorname{TOM}_{s_{1}}(j)\right)\left(s_{1}\right)\right] } \\
= & \lambda x_{1} \lambda s_{1} \cdot\left[\lambda s_{0}\left[\exists k\left[\lambda j\left[x_{1}(j) \wedge \operatorname{TOM}_{s_{1}}(j)\right](k) \wedge V(\text { he arrive })(k)\right]\right]\left(s_{1}\right)\right] \\
= & \lambda x_{1} \lambda s_{1} \cdot\left[\lambda s_{0}\left[\exists k\left[x_{1}(k) \wedge \operatorname{TOM}_{s_{1}}(k) \wedge V(\text { he arrive })(k)\right]\right]\left(s_{1}\right)\right] \\
= & \lambda x_{1} \lambda s_{1} \cdot \exists k\left[x_{1}(k) \wedge \operatorname{TOM}_{s_{1}}(k) \wedge V(\text { he arrive })(k)\right]
\end{aligned}
$$




\section{The tenses}

This section deals with the interpretation of Past and Present tense; in Section 5, I will turn the modal 'will'. I will first summarize some assumptions I make about both of these expressions.

\subsection{Past, non-past, and certainty}

There is little consensus on whether in English there is, in addition to Past and Present, a Future tense, and if so, how it is morphologically realized. Those who believe that there is, usually regard the auxiliary 'will' as its overt expression (Wekker, 1976; Bennett and Partee, 1978; Comrie, 1982, 1985; Hornstein, 1990; Kamp and Reyle, 1993; Gennari, 2003); alternatively, Steedman (2002) ascribes that role to Present morphology, which he assumes is ambiguous between Present and Future tense. Others reject the notion that English has a Future tense, noting that reference to future times is also realized by a variety of other grammatical means and generally inextricably intertwined with modality (Joos, 1964; Leech, 1971; Palmer, 1974, 1979; Dowty, 1979; Quirk et al., 1985; Huddleston and Pullum, 2002).

I adopt the latter view. The use of 'will' is neither necessary for future reference (recall 2a above, repeated below as 12) nor sufficient for it (as witnessed by examples like 'He will be here now'). Present tense, for instance, is another way of realizing future reference. But this raises another question: Is the Present morphology ambiguous, as Steedman would have it, or underspecified as "non-past" (cf. Quirk et al., 1985)? The latter position would be preferable inasmuch as it allows for a simpler semantic analysis, but its viability depends on whether the Certainty Condition can be explained independently.

The problem is that Present-tense morphology comes with the Certainty Condition only on its futurate use, when the reference time follows the speech time. The reference time is constrained by a variety of factors, including adverbials, context, and the aspectual properties of the sentence. With non-stative sentences like (12), the reference time always lies in the future, for reasons that I consider orthogonal to my present concerns. ${ }^{5}$

(12) He submits his paper to a journal.

\footnotetext{
${ }^{5}$ This paper is not committed to a particular analysis of aspect (or Aktionsart); the framework should be compatible with any account of the constraints that it contributes. One candidate would be Gennari's (2003) proposal that the Present induces a future reference time with all aspectual classes and that the co-temporal interpretation of statives is inferable via their "superinterval property."
} 
As a consequence, (12) generally carries the CC. On the other hand, stative sentences do not carry the $\mathrm{CC}$ with a present reference time (13a), but do with a future reference time $(13 \mathrm{~b})$.

(13) a. He is in his office (now).

b. He is in his office tomorrow.

Furthermore, the $\mathrm{CC}$ is not carried by sentences in the Past. Thus the generalization is that it does not arise with past and present reference times, but only with future reference times (relative to the speech time).

There is an obvious connection between this generalization and the motivation behind models of branching time. Leech (1971) notes that the futurate Present "attributes to the future the same degree of certainty that we normally accord to present and past events" (p. 65; cf. also Quirk et al., 1985). In line with this intuition, I propose a shift of perspective which makes a unified analysis of present and futurate uses of the Present not only viable, but virtually inevitable: It is not the case that the $\mathrm{CC}$ is only carried by the futurate Present. Rather, it is part of the interpration of all (non-modalized) sentences, Past and Present; but it is only with future reference that it contributes anadditional semantic component over and above the condition that the sentence be true.

Specifically, I assume that all sentences in the bare tenses contain a covert epistemic necessity operator and are evaluated against, or predicated of, metaphysical or doxastic modal bases. ${ }^{6}$ Thus their truth conditions involve either settledness or belief, not merely truth simpliciter. The fact that their use with future reference tends to be infelicitous is explained by this strong interpretation, since what is not settled at speech time cannot possibly be known. Recall that this follows from the conditions on doxastic histories in Definition 5 above.

The reader may wonder at this point why I choose to build this modal element into the truth conditions. This decision has a precedent in Dowty (1979, p. 158), although he includes it only for the bare Present. On the other hand, Steedman (2002) consigns it to pragmatics. Indeed, a prag-

\footnotetext{
${ }^{6}$ I use the term "epistemic" here in its linguistic sense. In this sense, "epistemic" modals are opposed to "root" (e.g., deontic) modals (Jackendoff, 1972; Hofmann, 1976; Brennan, 1993). There is some potential for confusion, since these "epistemic" modals may have epistemic, doxastic or metaphysical readings in the logical sense. I should also mention at this point that I do not intend the same analysis to apply to root modals. They appear to be embedded under epistemic modals of the kind I discuss here, hence semantically in the nuclear scope of the operator I introduce in the next section. Related to this is the observation that they do not seem to scope out of conditional consequents (Frank, 1996; Zvolenszky, 2002).
} 
matic alternative would seem possible and tempting. I will consider it in Section 7.3.1 and show that it is ultimately untenable in view of data from predictive conditionals.

Thus the bare Present combines a "non-past" temporal component with a universal modal force. In this modal component, it contrasts with overt modals like 'will', which I will turn to in Section $5 .^{7}$ Since my treatment of the tenses is partly motivated by that analysis, a brief preview is in order.

It is customary to decompose modals like 'will' into Present tense scoping over an abstract morpheme woll (Abusch, 1997, 1998; Condoravdi, 2002). I adopt this approach below, assuming that 'woll' contributes a modal force (which differs somewhat from the Certainty expressed by the bare tenses) whereas the tense contributes nothing but the meaning of "non-past." It is useful to separate these two semantic elements across the board, both for expository purposes and in the interest of a uniform analysis of the Present tense in sentences with and without overt modals. For the bare Present, I postulate an abstract modal element which I will label ' $\varnothing$ '. ${ }^{8}$ Thus a sentence like (14a) is represented as (14b).

(14) a. He comes tomorrow.

b. $\operatorname{PRES}(\varnothing($ tomorrow $($ he come $)))$

\subsection{Modal force}

Formally, the denotation of $\varnothing$ combines with the embedded sentence radical (possibly modified by frame adverbials) to form what will turn out to be in effect a generalized quantifier over indices. Its semantic type is given in (15). Recall that the type of the first argument, $\langle\langle s, t\rangle,\langle s, t\rangle\rangle$, is the type of sentence radicals.

$$
\langle\langle\langle s, t\rangle,\langle s, t\rangle\rangle,\langle\langle\langle s,\langle s, t\rangle\rangle,\langle\langle s,\langle s, t\rangle\rangle,\langle s,\langle s, t\rangle\rangle\rangle\rangle\rangle\rangle
$$

I introduce (for the case of $\varnothing$ ) a variant of the necessity operator ' $\square$ ' familiar from modal logic. It is used here as a two-place operator, both of whose arguments are of type $\langle s, t\rangle$, i.e., (characteristic functions of) sets of indices.

\footnotetext{
${ }^{7}$ I will not be dealing with 'must', which has been characterized as adding to the assertion the claim that it is supported by the available evidence only in some "indirect" fashion (Veltman, 1986; Stone, 1994; Westmoreland, 1995). I believe that this is basically correct; I will not discuss 'must' any further because the meaning just described makes it an evidential, placing it outside the scope of this paper.

${ }^{8}$ In my view, this analysis does not entail a commitment to a syntactic analysis of the bare Present which actually includes a morpheme meaning ' $\varnothing$ '. Perhaps the universal modal force is simply a default way of interpreting non-modalized sentences. On the other hand, phenomena like emphatic do-support do lend some support to the idea that there might be some syntactic motivation for this analysis.
} 


$$
\llbracket \varnothing \rrbracket=\lambda \varphi \lambda T \lambda R \lambda i \lambda s . \square(\lambda j . i R j)(\lambda j . \varphi(\lambda k . j T k)(s))
$$

The two arguments of ' $\square$ ' in (16) form its restriction and nuclear scope, respectively. The interpretation of the expression resulting from applying (16) to its arguments is as expected (I write ' $\Phi$ ', ' $\Psi$ ' etc. for functions of type $\langle s, t\rangle): \square(\Phi)(\Psi)=1$ iff for all indices $i^{\prime}$ such that $\Phi\left(i^{\prime}\right)$ is true, $\Psi\left(i^{\prime}\right)$ is true. The first argument, $\Phi$, anchors this evaluation to the perspective of a particular index ( $i$ in 16 above). As an example, consider (17), again spelled out in detail:

$$
\begin{aligned}
& \llbracket \varnothing(\text { tomorrow (he arrive })) \rrbracket \\
& =\lambda \varphi \lambda T \lambda R \lambda i_{2} \lambda s_{2} . \square\left(\lambda j . i_{2} R j\right)\left(\lambda j . \varphi(\lambda l . j T l)\left(s_{2}\right)\right) \\
& \left(\lambda x_{1} \lambda s_{1} . \exists k\left[x_{1}(k) \wedge \operatorname{TOM}_{s_{1}}(k) \wedge V(\text { he arrive })(k)\right]\right) \\
& =\lambda T \lambda R \lambda i_{2} \lambda s_{2} \cdot \square\left(\lambda j . i_{2} R j\right) \\
& \left(\lambda j\left[\lambda x_{1} \lambda s_{1} . \exists k\left[x_{1}(k) \wedge \operatorname{TOM}_{s_{1}}(k) \wedge V(\text { he arrive })(k)\right](\lambda l . j T l)\left(s_{2}\right)\right]\right) \\
& =\lambda T \lambda R \lambda i_{2} \lambda s_{2} \cdot \square\left(\lambda j . i_{2} R j\right) \\
& \left(\lambda j\left[\lambda s_{1} . \exists k\left[\lambda l[j T l](k) \wedge \operatorname{TOM}_{s_{1}}(k) \wedge V(\text { he arrive })(k)\right]\left(s_{2}\right)\right]\right) \\
& =\lambda T \lambda R \lambda i_{2} \lambda s_{2} \cdot \square\left(\lambda j . i_{2} R j\right) \\
& \left(\lambda j\left[\lambda s_{1} \cdot \exists k\left[j T k \wedge \operatorname{TOM}_{s_{1}}(k) \wedge V(\text { he arrive })(k)\right]\left(s_{2}\right)\right]\right) \\
& =\lambda T \lambda R \lambda i_{2} \lambda s_{2} . \square\left(\lambda j . i_{2} R j\right)\left(\lambda j . \exists k\left[j T k \wedge \operatorname{TOM}_{s_{2}}(k) \wedge V(\text { he arrive })(k)\right]\right)
\end{aligned}
$$

The resulting expression combines with two accessibility relations. These relations, signified by the variables $T$ and $R$ in (17), are temporal and modal, respectively.

\subsection{Tense}

Since the modal force is parceled out to the abstract element $\varnothing$, the translation of the tenses can be very simple: PRES and PAST denote non-past and past, respectively. Formally, they are accessibility relations, i.e., of type $\langle s,\langle s, t\rangle\rangle .^{9}$

(18) a. $\llbracket \mathrm{PRES} \rrbracket=\lambda i \lambda j . i \leq j$

b. $\llbracket \mathrm{PAST} \rrbracket=\lambda i \lambda j \cdot j<i$

The combination of (17) with Present tense is spelled out in (19). (I switch notations from ' $j T k$ ' to ' $T(j)(k)$ ' in mid-derivation for readability.)

\footnotetext{
${ }^{9}$ One could include at this point a means for incorporating contextually given reference times. To add a reference interval $r_{s},(18 \mathrm{a})$ is changed to ' $\llbracket \mathrm{PRES} \rrbracket=\lambda i \lambda j . i \leq j \wedge r_{s}(j)$ ', where $r$ is a variable of type $\langle s, t\rangle$ that is locally free but contextually bound; similarly for $(18 \mathrm{~b})$.
} 


$$
\begin{aligned}
& \llbracket \varnothing(\text { tomorrow }(\text { he arrive }))(\mathrm{PRES}) \rrbracket \\
&= \lambda T \lambda R \lambda i_{2} \lambda s_{2} . \square\left(\lambda j \cdot i_{2} R j\right)\left(\lambda j . \exists k\left[j T k \wedge \mathrm{TOM}_{s_{2}}(k) \wedge V(\text { he arrive })(k)\right]\right) \\
&(\lambda l \lambda m . l \leq m) \\
&= \lambda R \lambda i_{2} \lambda s_{2} \cdot \square\left(\lambda j . i_{2} R j\right) \\
&\left(\lambda j \cdot \exists k\left[\lambda l \lambda m[l \leq m](j)(k) \wedge \mathrm{TOM}_{s_{2}}(k) \wedge V(\text { he arrive })(k)\right]\right) \\
&= \lambda R \lambda i_{2} \lambda s_{2} \cdot \square\left(\lambda j . i_{2} R j\right) \\
&\left(\lambda j \cdot \exists k\left[\lambda m[j \leq m](k) \wedge \operatorname{TOM}_{s_{2}}(k) \wedge V(\text { he arrive })(k)\right]\right) \\
&= \lambda R \lambda i_{2} \lambda s_{2} \cdot \square\left(\lambda j . i_{2} R j\right)\left(\lambda j \cdot \exists k\left[j \leq k \wedge \mathrm{TOM}_{s_{2}}(k) \wedge V(\text { he arrive })(k)\right]\right)
\end{aligned}
$$

In the derivations that follow below, I will skip over simple reductions like that from ' $\lambda l \lambda m[l R m](j)(k)$ ' to ' $j R k$ ' in (19).

\subsection{Modal base}

Expressions like (19) require one more accessibility relation. This is the modal base, again of type $\langle s,\langle s, t\rangle\rangle$. It determines whether the sentence is asserted about (or evaluated against) historical alternatives or a belief state. I use the symbols ' $\approx$ ' and ' $\sim$ ' for metaphysical and doxastic modal bases, respectively. ${ }^{10}$

(20) a. $\lambda i \lambda j . i \approx j$

b. $\lambda i \lambda j . i \sim j$

The application of (19) to the objective accessibility relation is shown in (21).

$$
\begin{aligned}
& \llbracket \varnothing(\text { tomorrow }(\text { he arrive }))(\mathrm{PRES})(\approx) \rrbracket \\
&= \lambda R \lambda i_{2} \lambda s_{2} . \square\left(\lambda j . i_{2} R j\right)\left(\lambda j \cdot \exists k\left[j \leq k \wedge \mathrm{TOM}_{s_{2}}(k) \wedge V(\text { he arrive })(k)\right]\right) \\
&(\lambda l \lambda m . l \approx m) \\
&= \lambda i_{2} \lambda s_{2} . \square\left(\lambda j . i_{2} \approx j\right)\left(\lambda j . \exists k\left[j \leq k \wedge \operatorname{TOM}_{s_{2}}(k) \wedge V(\text { he arrive })(k)\right]\right)
\end{aligned}
$$

\footnotetext{
${ }^{10}$ Also like tenses, these arguments can be subject to contextually provided restrictions. This happens, for instance, in sequences of conditionals: Even if (b) is true in isolation, it is odd in the context of (a), where it tends to be interpreted as (c).

a. If I win a million, I will quit my job.

b. If I quit my job, I will be poor.

c. If I win a million and quit my job, I will be poor.

Such a restriction can be incorporated in much the same way as for the tenses, as a free variable which is then bound at the discourse level. I have no occasion to do so in this paper, however.
} 


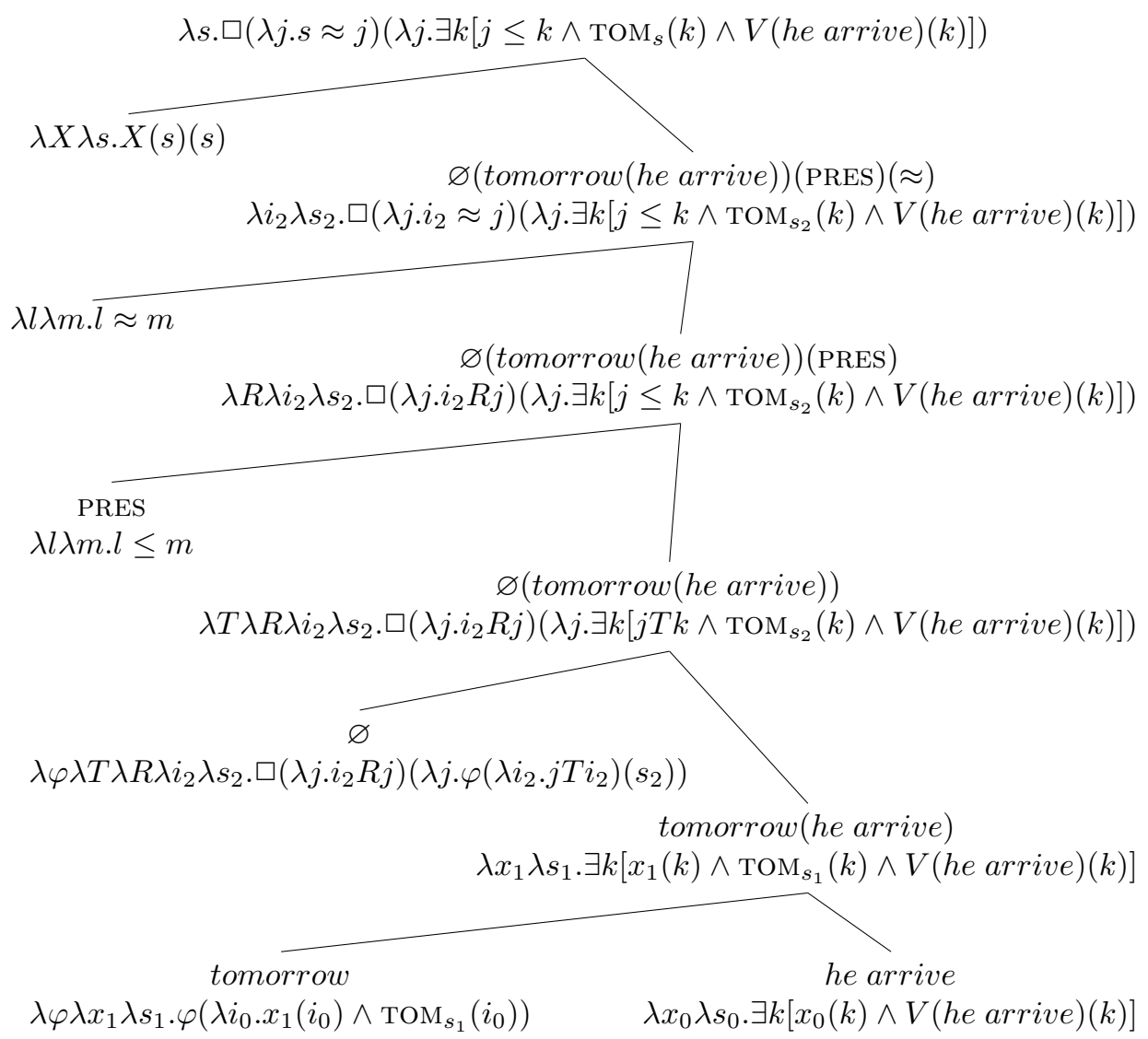

Figure 1: Derivation of 'He arrives tomorrow'

\subsection{Matrix clauses}

The last step is to turn (21) into (the characteristic function of) a proposition. This is accomplished by a special operation, which applies only to matrix clauses. Its sole purposes is to ensure that deictic frame adverbials are interpreted from the perspective of the speech time. The operator is of type $\langle\langle s,\langle s, t\rangle\rangle,\langle s, t\rangle\rangle$, defined as $\lambda X \lambda s . X(s)(s)$. (Here and below, I will use the dedicated variable ' $X$ ' to range over objects of type $\langle s,\langle s, t\rangle\rangle$ that are not modal or temporal accessibility relations.) It is easy to see that the application of this operation to (21) "synchronizes" $i_{2}$ and $s_{2}$ :

$$
\begin{aligned}
& \lambda X \lambda s[X(s)(s)](21) \\
& =\lambda s . \square(\lambda j . s \approx j)\left(\lambda j . \exists k\left[j \leq k \wedge \operatorname{TOM}_{s}(k) \wedge V(\text { he arrive })(k)\right]\right)
\end{aligned}
$$


Figure 1 recapitulates the derivation of this example. The resulting truth conditions for some particular index $s^{*}$ are as follows:

(23) $(22)\left(s^{*}\right)=1$

a. iff for all $j$ such that $s^{*} \approx j$, there is a $k$ such that $j \leq k$ and $\operatorname{TOM}_{s^{*}}(k)=1$ and $V($ he arrive $)(k)=1$;

b. iff it is settled at $s^{*}$ that he arrives on the next day.

Nothing requires the modal base in $(21)$ to be the objective accessibility relation $\approx$. The application to $\sim$ instead of $\approx$ corresponds to a different reading for the sentence, which, however, still implies settledness. For recall that due to the lack of foreknowledge of $\sim$, a sentence cannot be true throughout an agent's belief state without also being settled throughout that belief state. The sentence is peculiar regardless of the modal base, since this degree of certainty about the future can rarely be attained. In the following section I discuss the limited range of circumstances in which it can.

\subsection{Sources of certainty}

Three major ways in which the Certainty Condition may be satisfied have been discussed in the literature on the bare Present. The first is certainty that the sentence is actually true, typically in cases in which its truth can be deduced from past and present facts together with natural laws that are considered deterministic. This is the case in (24) from Goodman (1973).

(24) The sun sets at 8:39 tomorrow.

Such certainty is also involved in speech acts other than assertions. Both (25a) and $(25 \mathrm{~b})$, close grammatical relatives of $(24)$, suggest that the speaker, though ignorant of the truth value of (24), assumes that the question is already settled (and thus the answer can in principle be known). This is the attitude I called the "presumption of decidedness" in Section 2 above.

(25) a. Does the sun set at 8:39 tomorrow?

b. When does the sun set tomorrow?

The presumption of decidedness need not be common belief among the interlocutors in order for a sentence like (24) to be felicitous. It is sufficient for them to agree that it may already be settled. In (26), B's response entails the answer to A's question (and includes some extraneous information that $\mathrm{B}$ can reasonably expect to be of value to A). It is perfectly felicitous, even though A's very question shows that she entertains the possibility that the departure time may not yet be decided. 
(26) A: Has there been a decision on my itinerary?

B: You leave at 5:30 tomorrow.

The second kind of certainty likewise requires that the truth of the sentence be deducible, but from premises which for all the speaker knows might well be false. Consequently, it does not follow that the sentence is actually true, nor that the speaker believes that it is. This is the case in the typical "scheduling" reading, illustrated in (27). Suppose the speaker utters the sentence after taking a look at the timetable.

(27) The plane leaves at $4 \mathrm{pm} . .$.

a. but I doubt that it will.

b. \#but I doubt that it does.

The bare present in (27) conveys certainty about the contents of the timetable, as indicated by the infelicity of the continuation in (27b), but not about the actual departure time of the plane, as shown by both the non-contradictoriness of the continuation (27a) and the fact that (27b) has no felicitous alternative interpretation as a claim about the actual departure time. (27) with its continuation in (27a) is felicitous because it typically conveys that it is settled that the plane leaves at $4 \mathrm{pm}$ with respect to one modal base (the timetable) but not with respect to another (the facts).

The scheduling reading offers a strategy for listeners who are confronted with the assertion of a sentence whose truth value they believe is not yet settled. The repair consists in a reinterpretation of the sentence relative to a modal base with foreknowledge. ${ }^{11}$ What that modal base is depends on the preferences and expectations of the listener. This remedy is at work in Lakoff's (1971) example (28):

(28) a. The Yankees play the Red Sox tomorrow.

b. \#The Yankees play well tomorrow.

The difference in felicity is due to an underlying difference in the ease with which a suitable interpretation can be found under which the sentence is presumed decided. While it is natural to interpret (28a) as a statement about the published schedule, $(28 \mathrm{~b})$ requires more effort to find a plausible reinterpretation, likely one involving a secret agreement behind the scenes. A reinterpretation along these lines makes (28b) felicitous. It does not entail then, of course, that the Yankees actually do play well on the next day.

\footnotetext{
${ }^{11}$ For lack of space, I cannot discuss this reinterpretation in full detail. I only note that I believe the modal base (e.g., 'According to the schedule...') enters the nuclear scope of $\varnothing$, and that the whole sentence is still interpreted with respect to, for instance, the speaker's beliefs.
} 
The third kind of certainty is one that Edgington (1997) attributes to the "Almighty," and which is presumably available to speakers with foreknowledge. A sentence like (29) could only be used by such a being.

(29) It rains tomorrow.

Ordinary inhabitants of the world must base their predictions on the evidence available at speech time. In the case of weather patterns, such evidence is generally too inconclusive to support (29). A listener who accepts the Almighty's assertion of the sentence and updates her beliefs accordingly will end up with an inadmissible belief state under the above definitions unless, perhaps more rationally, she reinterprets the sentence as asserting that it rains tomorrow 'according to the Almighty'.

\section{The auxiliary 'will'}

The last section dealt with the interpretation of the bare tenses. The second element in the account is the interpretation of modals, among which I count the auxiliary 'will' on its relevant reading.

Discussions of 'will' often focus on the question of whether it is primarily a tense marker or a modal. It invariably comes with modal connotations, but this observation has led different authors to opposite conclusions. Some claim that it is a modal and that its association with future reference is a side effect of the particular modal force it is usually used to express (Joos, 1964; Palmer, 1974, and others). Others argue that it is a marker of futurity whose modal connotations are due to the uncertainty inherent in the future (Wekker, 1976). The question of whether it is one or the other loses some of its urgency if 'will' is treated as a hybrid modal-temporal complex 'PRES+WOLL', similar to 'PRES+ $\varnothing$ ', which operates in both dimensions. ${ }^{12}$

The main uses of 'will' are broadly divided between the meanings of prediction or expectation on one side and volition on the other, each with further subdivisions and perhaps with a blurry boundary between them (Leech, 1971; Palmer, 1974; Wekker, 1976; Quirk et al., 1985). I will focus exclusively on the predictive reading.

\subsection{Modal force}

As a first approximation, one might consider adopting a definition along the same lines as for $\varnothing$, saying that 'will' involves universal quantification

\footnotetext{
${ }^{12}$ The detailed semantic analysis of this operator is an ongoing endeavor. See Condoravdi (2003) for alternatives to some aspects of my proposal.
} 
over alternatives. This would result in an analysis of 'will' that makes it equivalent to the bare Present under my analysis.

In fact, however, 'will $\varphi$ ' makes a weaker claim, as shown by examples like the following. Suppose a fair coin is about to be tossed some large number of times. In such a scenario, (30a) is quite clearly true, whereas (30b) is odd, regardless of how many tosses are expected to be made.

(30) a. The coin will come up heads (eventually).

b. ?The coin comes up heads (eventually).

While (30a) makes a genuine prediction under uncertainty, (30b) can only mean that the coin is two-headed or the experiment is rigged in some other way. This contrast arises not only in artificial cases like (30), but quite generally, as in (31).

(31) a. It will rain tomorrow.

b. ?It rains tomorrow.

Such facts suggest that the modal force required for 'will' is somehow weaker than necessity. There are various formal ways of representing such a weaker force. Here I choose one that is familiar from Kratzer's (1981) work on graded modality. ${ }^{13}$

The idea is that in a sentence like (31a), not all historically or doxastically accessible indices are relevant for the truth of the sentence, but only those which satisfy certain defaults or "normalcy" assumptions. Such assumptions are represented as an ordering source in Kratzer's theory, a function from worlds to sets of propositions which, for each world $w$, returns the set of propositions that are "normally" true at $w$. This is just an intermediate step, however: Ultimately, the role of the ordering source is to induce a pre-order on possible worlds which ranks them according to their relative likelihood: ${ }^{14}$ World $w^{\prime \prime}$ is at least as likely as world $w^{\prime}$ from the perspective of $w$ if and only if all the propositions associated with $w$ by the ordering source which are true at $w^{\prime}$, are also true at $w^{\prime \prime}$.

Translated into the current setup, the objects which are ranked in this way are not worlds, but indices. For simplicity, I will skip the indirect definition in terms of sets of propositions and instead represent ordering sources directly as functions from indices to pre-orders between indices.

\footnotetext{
${ }^{13}$ An earlier version of this paper offered a probabilistic treatment at this point. The change is due to space constraints and does not constitute a retraction of the earlier account.

${ }^{14}$ The term "relative likelihood" was applied to such pre-orders by Halpern $(1997,2003)$.
} 


\section{Definition 8 (Ordering source)}

An ordering source is a relation $O$ in $I \times I \times I$ such that for all $i \in I, O_{i}$ is reflexive and transitive.

I use the variable ' $O$ ' to range over ordering sources, and ' $\preccurlyeq$ ', ' $\preccurlyeq$ ' etc. to denote particular instances. The intended reading of ' $j \preccurlyeq_{i} k$ ' is ' $k$ is at least as likely (from the perspective of $i$ ) as $j$ '. Notice that $\preccurlyeq_{i}$ is not restricted to indices that are cotemporal with $i$. For now, this generality appears useless, since the domain on which the order becomes relevant has so far been defined in terms of modal accessibility relations. Below, however, in dealing with predictive conditionals, it will be necessary to compare arbitrary pairs of indices, so this property of $\preccurlyeq i$ will be needed.

The ordering source enters the interpretation of a newly defined binary operator ' $\square$ ', similar to ' $\square$ ' but sensitive to relative likelihood: $\sigma_{i}(\Phi)(\Psi)=$ 1 iff for all $i^{\prime}$ such that $\Phi\left(i^{\prime}\right)$, there is some $i^{\prime \prime}$ such that $\Phi\left(i^{\prime \prime}\right)$ and $i^{\prime} O_{i} i^{\prime \prime}$ and $\Psi\left(i^{\prime \prime}\right)$.

\subsection{The modal 'WOLL'}

As I mentioned above, I assume that 'will' consists of the abstract element WOLL under the scope of Present tense. WOLL contributes the modal force defined in the previous section. The non-past reference interval is contributed by PRES. Thus 'will $\varphi$ ' is analyzed as $\operatorname{PRES}(\operatorname{WOLL}(\varphi))$, contrasting with $\operatorname{PRES}(\varnothing(\varphi))$ and differing from the latter only in its modal force. This difference in modal force explains the preference for the use of 'will' over the bare Present in the case of future reference: Not only is $\operatorname{PRES}(\operatorname{WOLL}(\varphi))$ semantically weaker than $\operatorname{PRES}(\varnothing(\varphi))$, but the latter is rarely true at all, except in the special cases discussed in Section 4.6. The interpretation of WOLL is given in (32). It combines with an ordering source $O$; once this ordering source is supplied, the result is of the same type as the denotation of $\varnothing .^{15}$

\footnotetext{
${ }^{15}$ The temporal component attributed to wOLL in Definition (32) ignores the forwardshifting effect it has on the reference interval even without the Present tense, as observed in Past-tense 'would'. To take it into account, we would need an explicit representation of the reference time (see Footnote 9). Part of the meaning of wOLL would then consist in an extension of this reference time into the future. The intersective meaning of the tenses would ensure that this indefinitely extended reference interval is cropped at speech time with the Past tense but left intact with the Present (see also Condoravdi, 2003). I will not explore this matter further here. Definition 32 suffices for my purposes.

An anonymous reviewer suggests that 'will' necessarily shifts the reference time forward. I am not sure if such a strong claim is warranted. The temporal behavior of 'will' resembles in some respects that of the bare Present. The fact that for the truth of (ia) it is not
} 


$$
\llbracket \mathrm{WOLL} \rrbracket=\lambda O \lambda \varphi \lambda T \lambda R \lambda i \lambda s . O_{i}(\lambda j . i R j)(\lambda j . \varphi(\lambda k . j T k)(s))
$$

Once the ordering source is supplied, the derivation proceeds just as with the bare Present. Consider (33), the modalized counterpart of (22).

(33) He will arrive tomorrow.

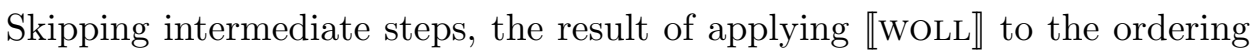
source $\preccurlyeq$ and the temporally modified sentence radical (17) is the following.

$$
\begin{aligned}
& \llbracket \operatorname{WOLL}(\preccurlyeq)(\text { tomorrow }(\text { he arrive })) \rrbracket \\
& =\lambda T \lambda R \lambda i_{2} \lambda s_{2} \cdot \preccurlyeq_{i_{2}}\left(\lambda j . i_{2} R j\right)\left(\lambda j . \exists k\left[j T k \wedge \operatorname{TOM}_{s_{2}}(k) \wedge V(\text { he arrive })(k)\right]\right)
\end{aligned}
$$

With tense, modal base and speech time supplied, and the matrix operator applied as before, this yields (35):

$$
\lambda s . \varpi_{s}(\lambda j . s \approx j)\left(\lambda j \cdot \exists k\left[j \leq k \wedge \operatorname{TOM}_{s}(k) \wedge V(\text { he arrive })(k)\right]\right)
$$

The derivation is as in Figure 1, except for the difference in modal force.

\section{Conditionals}

The preceding sections dealt with the simple sentences that appear as the constituents of conditionals. In this section I will complete the picture by offering an interpretation for the conditional connective IF. I assume that IF combines with the antecedent to form a modifier for the consequent; its semantic role consists in imposing a constraint on the accessibility relation

suffient that John be crying now, is paralleled in the fact that (ia') must have a future reference time. But like the bare Present, 'will' can occur with present reference times in stative sentences; $c f .\left(i b, b^{\prime}\right)$. This suggests that the reason why (ia) cannot have a present reference time has to do with the aspectual properties of the predicate, not (only) the semantics of 'will'.

$$
\begin{array}{ll}
\begin{array}{ll}
\text { a. John will cry. } & \text { a'. ?John cries. } \\
\text { b. John will be in his office (now). } & \text { b'. John is in his office (now). } \\
\text { c. John will be in his office tomorrow. } & \text { c'. ?John is in his office tomorrow. }
\end{array}
\end{array}
$$

I do not deny the close association of 'will' with future reference, but neither do I conclude that 'will' is not compatible with present reference. It seems, rather, that it is more generally associated with lack of certainty. My truth conditions do not incorporate this (sentences with 'will' are entailed by their bare-Present counterparts) because I consider it a pragmatic effect: Since 'will' is both semantically weaker and morphologically more complex than the bare Present, it implicates the denial of the latter. Together with the assumptions built into the model, this predicts that with past and present reference times, 'will' generally receives a subjective reading (see Section 7.5 below). These matters certainly deserve more exploration, which I however do not attempt here. 
of the matrix clause. This basic idea has been entertained before (eg. von Fintel, 1994). The contribution of this paper is the detailed compositional account of the constraints imposed on the available readings for the conditional by the interplay between the temporal and modal elements.

More specifically, the complex 'IF+antecedent' combines with the consequent at a point in the derivation at which the latter has received its modal force and its tense, but is yet to be applied to (or predicated of) a modal base. The role of the 'if'-clause is to ensure that whatever that modal base is, the consequent is only evaluated at those indices at which the antecedent is true.

The type of the consequent, at the point at which it is modified by the 'if'-clause, is $\langle\langle s,\langle s, t\rangle\rangle,\langle s,\langle s, t\rangle\rangle\rangle$. This function becomes the argument of the 'if'-clause, and spelling out the definition requires a variable of this type. I will use the Greek letter $\zeta$ for this purpose.

For reasons I will discuss below, I assume that the antecedent, when it combines with IF, is not of the same type as $\zeta$. Instead, it receives its own modal base before it enters the conditional, thus its derivation is almost complete, except for the application of the matrix operator which synchronizes speech time and evaluation time. So the type of the antecedent is $\langle s,\langle s, t\rangle\rangle$. The type of IF is the following:

$$
\langle\langle s,\langle s, t\rangle\rangle,\langle\langle\langle s,\langle s, t\rangle\rangle,\langle s,\langle s, t\rangle\rangle\rangle,\langle\langle\langle s,\langle s, t\rangle\rangle,\langle s,\langle s, t\rangle\rangle\rangle\rangle\rangle
$$

These remarks apply to both non-predictive and predictive interpretations of conditionals. The formal difference between these readings is minimal, but in the interest of clarity, I will deal with each in turn.

\subsection{Non-predictive conditionals}

A first definition of IF is given in (37). Recall that $X$ ranges over objects of type $\langle s,\langle s, t\rangle\rangle$.

$$
\llbracket \mathrm{IF} \rrbracket=\lambda X \lambda \zeta \lambda R \lambda i \lambda s . \zeta(\lambda l \lambda m . l R m \wedge X(m)(s))(i)(s)
$$

For illustration, I will step through the derivation of (38). We will see that by using the interpretation of IF from Definition 37, we obtain a non-predictive reading.

(38) If he arrives tomorrow, he left yesterday.

Writing out derivations involving IF in full detail becomes a bit cumbersome. I will abbreviate the antecedent with the constant $A$, whose denotation is given in (21) above. The combination of IF with $A$ is straightforward; in (39), $\llbracket A \rrbracket$ is "unpacked" in the last line. 
(39) $\llbracket \operatorname{IF}(A) \rrbracket$

$$
\begin{aligned}
= & \lambda X \lambda \zeta \lambda R \lambda i_{3} \lambda s_{3}\left[\zeta\left(\lambda l \lambda m . l R m \wedge X(m)\left(s_{3}\right)\right)\left(i_{3}\right)\left(s_{3}\right)\right](\llbracket A \rrbracket) \\
= & \lambda \zeta \lambda R \lambda i_{3} \lambda s_{3} \cdot \zeta\left(\lambda l \lambda m . l R m \wedge \llbracket A \rrbracket(m)\left(s_{3}\right)\right)\left(i_{3}\right)\left(s_{3}\right) \\
= & \lambda \zeta \lambda R \lambda i_{3} \lambda s_{3} . \\
& \zeta\left(\begin{array}{l}
\quad l \lambda m . l R m \wedge \\
\square(\lambda j . m \approx j) \\
\quad\left(\lambda j . \exists k\left[j \leq k \wedge \mathrm{TOM}_{s_{3}}(k) \wedge V(\text { he arrive })(k)\right]\right)
\end{array}\right)\left(i_{3}\right)\left(s_{3}\right)
\end{aligned}
$$

(40) gives the denotation of the consequent at the relevant stage, tensed and with modal force, but as yet without a modal base:

$$
\lambda R_{0} \lambda i_{0} \lambda s_{0} \cdot \square\left(\lambda j . i_{0} R_{0} j\right)\left(\lambda j . \exists k\left[k<j \wedge \operatorname{YEST}_{s_{0}}(k) \wedge V(\text { he leave })(k)\right]\right)
$$

Feeding (40) into (39) yields (41), which simplifies as shown. I align some sub-formulas for readability, switch again from the notation ' $i_{0} R_{0} j$ ' to ' $R_{0}\left(i_{0}\right)(j)$ ', and "unpack" $\llbracket A \rrbracket$ in the last line.

$$
\begin{aligned}
& \llbracket \operatorname{IF}(A)(\varnothing(\text { yesterday }(\text { he leave }))(\mathrm{PAST})) \rrbracket \\
& =\lambda \zeta \lambda R \lambda i_{3} \lambda s_{3}\left[\zeta\left(\lambda l \lambda m . l R m \wedge \llbracket A \rrbracket(m)\left(s_{3}\right)\right)\left(i_{3}\right)\left(s_{3}\right)\right] \\
& \left(\lambda R_{0} \lambda i_{0} \lambda s_{0} . \square\left(\lambda j . i_{0} R_{0} j\right)\left(\lambda j . \exists k\left[k<j \wedge \operatorname{YEST}_{s_{0}}(k) \wedge V(\text { he leave })(k)\right]\right)\right) \\
& =\lambda R \lambda i_{3} \lambda s_{3} \\
& {\left[\begin{array}{c}
\lambda R_{0} \lambda i_{0} \lambda s_{0} \cdot \square\left(\lambda j \cdot i_{0} R_{0} j\right) \\
\left(\lambda j \cdot \exists k\left[k<j \wedge \operatorname{YEST}_{s_{0}}(k) \wedge V(\text { he leave })(k)\right]\right) \\
\left(\lambda l \lambda m . l R m \wedge \llbracket A \rrbracket(m)\left(s_{3}\right)\right)\left(i_{3}\right)\left(s_{3}\right)
\end{array}\right]} \\
& =\lambda R \lambda i_{3} \lambda s_{3}\left[\begin{array}{c}
\lambda i_{0} \lambda s_{0} \cdot \square\left(\lambda j \cdot i_{0} R j \wedge \llbracket A \rrbracket(j)\left(s_{3}\right)\right) \\
\left(\lambda j \cdot \exists k\left[k<j \wedge \operatorname{YEST}_{s_{0}}(k) \wedge V(\text { he leave })(k)\right]\right) \\
\left.\left(i_{3}\right)\left(s_{3}\right) \quad\right]
\end{array}\right]
\end{aligned}
$$

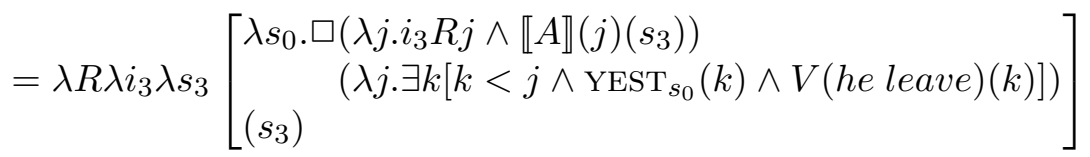

$$
\begin{aligned}
& =\lambda R \lambda i_{3} \lambda s_{3}\left[\begin{array}{c}
\square\left(\lambda j \cdot i_{3} R j \wedge \llbracket A \rrbracket(j)\left(s_{3}\right)\right) \\
\left(\lambda j \cdot \exists k\left[k<j \wedge \operatorname{YEST}_{s_{3}}(k) \wedge V(\text { he leave })(k)\right]\right)
\end{array}\right] \\
& =\lambda R \lambda i_{3} \lambda s_{3} \\
& {\left[\begin{array}{c}
\square\left(\lambda j \cdot i_{3} R j \wedge \square\left(\lambda j^{\prime} \cdot j \approx j^{\prime}\right)\right. \\
\left.\left(\lambda j^{\prime} \cdot \exists k\left[j^{\prime} \leq k \wedge \operatorname{TOM}_{s_{3}}(k) \wedge V(\text { he arrive })(k)\right]\right)\right) \\
\left(\lambda j . \exists k\left[k<j \wedge \operatorname{YEST}_{s_{3}}(k) \wedge V(\text { he leave })(k)\right]\right)
\end{array}\right]}
\end{aligned}
$$

The application of (41) to an epistemic modal base results in (42). 


$$
\begin{aligned}
& \llbracket(41) \rrbracket(\lambda l \lambda m . l \sim m) \\
& =\lambda i_{3} \lambda s_{3} \cdot\left[\begin{array}{c}
\square\left(\lambda j . i_{3} \sim j \wedge \llbracket A \rrbracket(j)\left(s_{3}\right)\right) \\
\left(\lambda j . \exists k\left[k<j \wedge \operatorname{YEST}_{s_{3}}(k) \wedge V(\text { he leave })(k)\right]\right)
\end{array}\right]
\end{aligned}
$$

The final result, after the derivation is closed off with the matrix operator, is (43).

$$
\begin{aligned}
\begin{aligned}
\lambda X \lambda s[ & X(s)(s)](42) \\
=\lambda s . \square & (\lambda j . s \sim j \wedge \llbracket A \rrbracket(j)(s)) \\
& \left.\left(\overline{\lambda j . \exists k\left[k<j \wedge \mathrm{YEST}_{s}\right.}(k) \wedge V(\text { he leave })(k)\right]\right) \\
=\lambda s . \square & \left(\lambda j . s \sim j \wedge \square\left(\lambda j^{\prime} \cdot j \approx j^{\prime}\right)\right. \\
& \left.\left(\lambda j^{\prime} \cdot \exists k\left[j^{\prime} \leq k \wedge \operatorname{TOM}_{s}(k) \wedge V(\text { he arrive })(k)\right]\right)\right) \\
& \left(\lambda j . \exists k\left[k<j \wedge \mathrm{YEST}_{s}(k) \wedge V(\text { he leave })(k)\right]\right)
\end{aligned}
\end{aligned}
$$

Ultimately, the contribution of the antecedent to the overall interpretation of the sentence is limited to the restrictor of the modal operator, the underlined part of (43). A tree illustrating the derivation of this example is given in Figure 2. The truth conditions are spelled out in (44).

(44) $(43)\left(s^{*}\right)=1$

a. iff for all $j$ such that $s^{*} \sim j$ and $A(j)=1$, there is a $k$ such that $k<j$ and $\operatorname{YeST}_{s^{*}}(k)=1$ and $V$ (he arrive) $(k)=1$;

b. iff for all $j$ such that (i) $s^{*} \sim j$ and (ii) [for all $j^{\prime}$ such that $j \approx j^{\prime}$, there is a $k^{\prime}$ later than $j^{\prime}$ and within the day following $s^{*}$ such that he arrives at $k^{\prime}$, there is a $k$ earlier than $j$ and within the day preceding $s^{*}$ such that he leaves at $k$;

c. iff it is known at speech time that he left on the previous day at all worlds at which it is settled at speech time that he arrives on the following day.

One property of the interpretation given in (44) deserves special emphasis: The condition added by the antecedent to the restrictor is a fully tensed and modalized sentence. In the above notation, this sentence is evaluated at indices $j$ accessible from $s^{*}$ via $\sim$. Since $\sim$ is a modal accessibility relation, each such $j$ is cotemporal with $s^{*}$. Due to the modal force in $(44 \mathrm{~b})$, what is checked is not whether it is true (simpliciter) at $j$ that the person arrives at the future time in question, but whether it is settled at speech time. Thus the antecedent can be paraphrased as 'If it is (now) settled that he comes tomorrow...'

For non-predictive readings, the definition in (37) is appropriate. The generalization to predictive conditionals involves a slight conceptual complication but is formally very straightforward. 


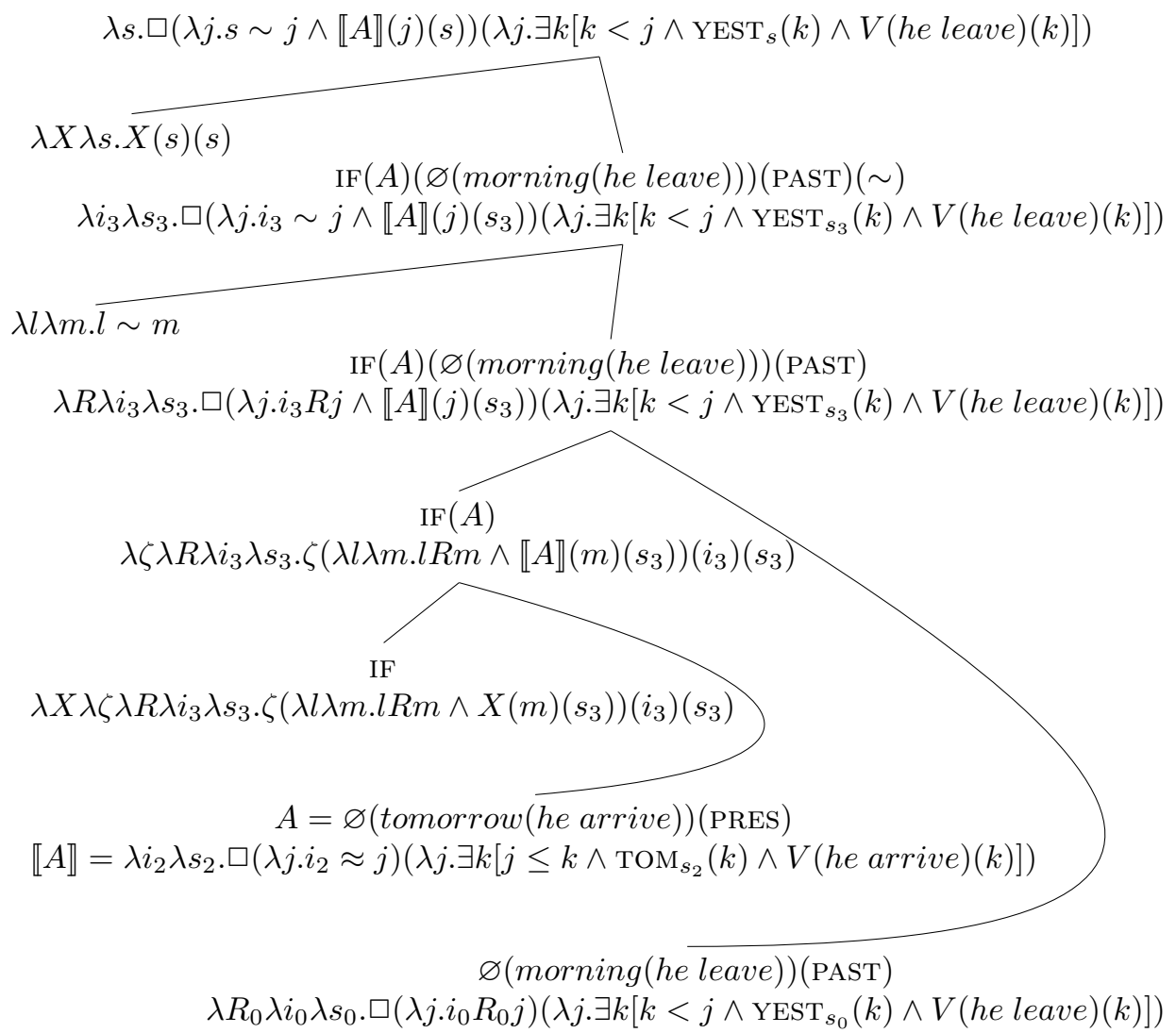

Figure 2: Derivation of (38)

\subsection{Predictive conditionals}

The only change in moving to predictive conditionals concerns the set of indices at which the constituents are evaluated: They are cotemporal with $s^{*}$ for for non-predictive conditionals, but may lie in the future in the predictive case.

I first define the notion of the "forward extension" of a modal base.

Definition 9 (Forward extension of modal bases)

Let $R$ be a modal accessibility relation. The forward extension of $R$, denoted by $R^{*}$, is defined as follows: $i R^{*} j$ if and only if for some $k, i R k$ and $k \leq j$.

In other words, $R^{*}$ is $R \circ \leq$, the composition of $R$ with temporal precedence. Intuitively, from the index $i$ of evaluation it can access indices "diagonally," covering both cotemporal and subsequent moments at all worlds accessible 
from $i$ via $R$.

This new accessibility relation, being of the same type as $R$ itself, does not necessitate any modifications to the formal setup. The generalization of IF to the predictive case merely involves the addition of the star. The role of the restriction ' $e_{s}(m)$ ' in (45) will be explained momentarily.

$$
\llbracket \mathrm{IF} \rrbracket=\lambda X \lambda \zeta \lambda R \lambda i \lambda s . \zeta\left(\lambda l \lambda m . e_{s}(m) \wedge l R^{*} m \wedge X(m)(s)\right)(i)(s)
$$

In the derivation (38), the result of using (45) instead of the "unstarred" version (37) is similarly straightforward. Only the last line is given in (46):

$$
\begin{gathered}
\lambda s . \square\left(\lambda j \cdot e_{s}(j) \wedge s \sim^{*} j \wedge \llbracket A \rrbracket(j)(s)\right) \\
\left(\lambda j . \exists k\left[k<j \wedge \mathrm{YEST}_{s}(k) \wedge V(\text { he leave })(k)\right]\right) \\
=\lambda s . \square\left(\lambda j \cdot e_{s}(j) \wedge s \sim^{*} j \wedge\right. \\
\square\left(\lambda j^{\prime} \cdot j \approx j^{\prime}\right) \\
\left.\left(\lambda j^{\prime} \cdot \exists k\left[j^{\prime} \leq k \wedge \operatorname{TOM}_{s}(k) \wedge V(\text { he arrive })(k)\right]\right)\right) \\
\left(\lambda j . \exists k\left[k<j \wedge \operatorname{YEST}_{s}(k) \wedge V(\text { he leave })(k)\right]\right)
\end{gathered}
$$

With the move from $R$ to $R^{*}$, the antecedent in (46) can now be paraphrased as 'If it is settled (now or at some future time) that he arrives tomorrow...'.' Notice, however, that the Present tense in the antecedent restricts the eligible future times to ones no later than 'tomorrow'.

An important feature of this analysis, from the point of view of compositionality, is that while the antecedent is interpreted literally at each accessible index $j$, without any special treatment of the temporal and modal impact of its bare present tense, it is not required that there be any worlds at which the question whether he comes or not is already settled at the time of $s$. This is because with $\sim^{*}$, the index $j$ at which $A$ is evaluated may lie in the future from the perspective of $s$.

It also becomes clear now why it is important to make special provisions for the availability of the global index of evaluation $s$ to TOM and YEST, the adverbials in the constituents. 'Tomorrow', for instance, should not end up being interpreted as $\operatorname{TOM}_{j}$, which would be the case if it were given the local evaluation time of the antecedent. This would wrongly result in the interpretation 'If it is settled (now or later) that he arrives the next day... '. ${ }^{16}$ Likewise for 'yesterday' in the consequent.

In principle, the relation $R^{*}$ may reach arbitrarily far into the future. However, the tenses of both antecedent and consequent, their reference times, temporal frame adverbials, and the fact that the antecedent is most

\footnotetext{
${ }^{16}$ There may well be languages in which the word for 'tomorrow' has such a logophoric use, but English is not one of them.
} 
typically not settled ahead of time, all conspire to impose more or less tight restrictions on this range, in ways which I will explore in some detail below.

In addition, the unbound variable $e_{s}$ of type $\langle s, t\rangle$ (mnemonic for "evaluation time" $\left.{ }^{17}\right)$ is a placeholder for a contextually given parameter imposing further restrictions on the range of $R^{*}$. That such contextual restrictions exist is shown by sentences like (47). Here the relevant time of evaluation is restricted by the context to fall between 'tonight' and 'tomorrow'.

(47) [Let's wait for today's decision regarding his travel arrangements.]

Then, If he arrives tomorrow, we'll book his room tonight.

This sentence can be paraphrased as 'If it is settled (later today) that he arrives tomorrow...' It clearly shows that the Certainty Condition is part of the interpretation of the antecedent even in predictive conditionals.

\subsection{Relative likelihood}

Turning once again the the modalized case, we can now cash in on the definition of $\preccurlyeq$ as returning, for each index $i$, an order on indices that is not restricted to those that are cotemporal with $i$. No modification in the definition of the operator $O$ is required in order for it to function as desired with the relation $R^{*}$. Consider the sentence in (48), whose interpretation is given in (49).

(48) If he leaves today, he will arrive tomorrow.

$$
\begin{gathered}
\lambda s . \Omega_{s}\left(\lambda j . e(j) \wedge s \sim^{*} j \wedge\right. \\
\square\left(\lambda j^{\prime} \cdot j \approx j^{\prime}\right) \\
\left.\left(\lambda j^{\prime} . \exists k\left[j^{\prime} \leq k \wedge \operatorname{TOD}_{s}(k) \wedge V(\text { he leave })(k)\right]\right)\right) \\
\left(\lambda j . \exists k\left[j \leq k \wedge \operatorname{TOM}_{s}(k) \wedge V(\text { he arrive })(k)\right]\right)
\end{gathered}
$$

The truth conditions of this formula can be paraphrased as follows:

(50) $(49)\left(s^{*}\right)=1$ iff for all $j$ such that (i) $s^{*} \sim^{*} j$ and (ii) it is settled at $j$ that he leaves no earlier than $j$ and within the day containing $s^{*}$, there is a $j^{\prime}$ such that (i) $s^{*} \sim^{*} j^{\prime}$ and (ii) it is settled at $j^{\prime}$ that he leaves no earlier than $j^{\prime}$ and within the day containing $s^{*}$ and (iii) there is a $k$ no earlier than $j^{\prime}$ and within the day following $s^{*}$ such that he arrives at $k$.

\footnotetext{
${ }^{17}$ Or, if one prefers Garrett's (2001) term, the "time of enlightenment." It also resembles Crouch's (1993) "temporal deictic center."
} 
Now suppose there are indices at doxastically accessible worlds and in the relevant time range (no earlier than speech time but within the same day) at which the subject leaves and later runs into some disaster, such as a heavy storm or a car breakdown, which delays his arrival. The conditional is still true if each such index is outranked in normalcy by one at which he leaves and arrives as expected.

Suppose again that the trip takes more than a full day, so that the subject cannot make it to his destination if he leaves too late in the afternoon. Again, the conditional is still true if he is expected to leave earlier, i.e., if each of the late indices is outranked in normalcy by an earlier one (not necessarily at the same world) at which he leaves and arrives as planned. Notice that for this to follow, it is essential that the ordering source compare indices across different times.

In sum, (48) is true as long as it is expected that if the subject leaves today, he most likely does so on time and without encountering any unforeseeable difficulties along the way. In contrast, either of the above falsifying circumstances renders (51) false.

(51) ?If he leaves today, he arrives tomorrow.

Since the presence of such falsifying circumstances usually cannot be ruled out, the strong claim made by this sentence is generally not warranted, hence the sentence sounds odd.

\section{Discussion}

The development of the formal setup is now complete. In this section I will discuss how it accounts for the various interpretive possibilities of conditionals. I will largely spare the reader the tedium of going through formally explicit truth conditions, only highlighting those aspects which are relevant to the examples at hand.

\subsection{Future perspective}

The reader may ask why the forward shift in evaluation time - the modification of $R$ to $R^{*}$ - is introduced here by the interpretation of IF, rather than the modal in the consequent. The latter approach would align my treatment for predictive conditionals with extended-now theories of 'will', such as Abusch's (1997; 1998) "n-expanding" account. Abusch attributes the well-formedness of Past and Present tense with reference to future events, exemplified in (52), to the presence of 'will' in the matrix clause. 
(52) On March 1, we will discuss the abstracts which were/are submitted by email.

The present paper is silent on this issue, although one way to tackle it suggests itself within the current approach, namely by endowing WOLL, like IF, with the ability to forward-extend the modal base (cf. also Footnote 15). However, this modification alone would not generalize to a full treatment of predictive conditionals. The forward shift cannot be due to the presence of 'will' in the consequent, because it arises with other forms as well. The following examples (53 is cited here from Crouch, 1993) illustrate this. ${ }^{18}$

(53) If I smile when I get out, the interview went well

(54) Take a small ball of dough and drop it in a glass of cold water. If it floats, you did it right.

(55) Where a 45-win season would have seemed like a terrific accomplishment before the season began, now there's a feeling that if they don't win 55 games, something went wrong. [NYT 01/24/95]

In these sentences, the consequent refers to a future time, but the Past tense is licensed nevertheless because it is evaluated from the perspective of a still more distant future. In these examples, it is not clear what, if not IF itself, would trigger the forward shift of the evaluation time.

The future evaluation time also provides the perspective for antecedent tenses other than the Present. Consider (56), which in an appropriate context may have a reading under which both the (hypothetical) arriving and the leaving of the subject occur in the future from the perspective of the speech time ('If it turns out that she arrived in the morning...').

(56) If she arrived in the morning, she left the night before.

These examples show that the forward shift in temporal perspective must be attributed to the conditional construction itself, rather than the modal 'will' in the consequent.

\subsection{Accessibility relations}

The interpretation I gave for IF does not require the antecedent and consequent of a conditional to share the same accessibility relation. The antecedent enters the derivation fully equipped with its own modal base. This

\footnotetext{
${ }^{18}$ Here and below, the labels NYT and wsJ indicate the corpora in which the examples are attested (New York Times and Wall Street Journal, respectively).
} 
is not forced on me by the formalism, but it seems to be the right approach in view of examples in which the modal bases for antecedent and consequent are clearly different, such as (57).

(57) If Paul will be alone on Christmas Day, he will let us know.

Although (57) does have an interpretation which evaluates both constituents with respect to the speaker's epistemic state ('I expect that if I come to expect Paul to be alone on Christmas Day...'), this is not the only interpretation, and not even a prominent one. On its most natural reading, the sentence asserts that the speaker expects Paul to get in touch if (and when) Paul thinks he will be alone on Christmas Day. To capture this reading, the constituents should not be required by definition to share the same modal base.

It is also worth pointing out in this connection that the formal separation between objective and subjective accessibility relations is crucial for the proper analysis of certain conditionals that are problematic for simpler accounts. Consider a conceivable alternative according to which all conditionals would be interpreted uniformly with respect to the speaker's epistemic state, as is the case, for instance, in Data Semantics (Veltman, 1985, 1986; Crouch, 1993). The analog of Data Semantics in the present framework would correspond to the assumption that all sentences are evaluated is uniformly with respect to $\sim$. However, this approach is unable to account for sentences like (58a), a variant of an example attributed to Richmond Thomason by van Fraassen (1980), and (58b) from Lewis (1986).

(58) a. If my wife deceives me, I won't believe it.

b. If Reagan works for the KGB, I'll never believe it.

Both of $(58 \mathrm{a}, \mathrm{b})$ may be true, even though they would be patently contradictory if the antecedent could only be interpreted as 'If I learn that...' Thus the modality with respect to which the antecedent is evaluated must be independent of that of the consequent, and it must be possible for it to be objective. ${ }^{19}$

\footnotetext{
${ }^{19}$ The example of Thomason's on which (58a) is based is (ia):

(i) a. If my wife is deceiving me, I will believe that she is not.

b. If I find out that my wife is deceiving me, I will believe that she is not.

c. If my wife is deceiving me (currently), I believe that she is not.

This sentence arguably has a separate reading, brought out in (ib), according to which the speaker resolves to turn a blind eye on his wife's transgressions, if any; however, this involves a different reading of 'will' which I am not concerned with in this paper.
} 


\section{3 $\quad$ Futurate antecedents}

Regarding conditionals whose antecedent refers to a time later than the consequent, I would like to address two issues. The first concerns the modal bases with respect to which the antecedent can be interpreted, the second the case of antecedents with the modal 'will'. I will discuss these in turn.

\subsubsection{A blind Ockhamist alley}

In the discussion of the operator $\varnothing$ included in the semantics of the bare Present, I limited the modal accessibility relations which may provide the restriction of the quantification to ones which lack foreknowledge (i.e., doxastic or metaphysical ones). This rules out a third possibility which would appear plausible at first, and on which I based an earlier proposal concerning predictive conditionals (Kaufmann, 2002) which I hereby retract. This alternative approach, recast in the current framework, would use the identity relation on indices as a modal base for the interpretation of the Present. Since necessity with respect to this relation corresponds to truth simpliciter, rather than settledness, I dub it the "Ockhamist" interpretation. ${ }^{20}$ Even though it is ultimately untenable, it is superficially attractive, therefore I will devote some space to its rebuttal.

The Ockhamist interpretation is attractive because in combination with reasonable pragmatic assumptions, it seems to offer an elegant explanation of some of the facts about the Certainty Condition observed earlier. Briefly put, the story goes as follows: The truth of sentences with bare tenses (Present and Past) is Ockhamist truth, thus (59a) is already true (at speech time) at just those indices at which he submits his paper at the future time in question. No reference to settledness is involved.

(59) a. He submits his paper to a journal.

b. If he submits his paper to a journal, we won't include it in our book.

(ia) does not pose a problem on its predictive reading, despite the fact that the conditions on doxastic states deprive the speaker of the ability to conceive of the possibility that a sentence he believes to be false may be objectively true. For (ia) is a conditional prediction about future beliefs which the speaker may not yet have at present.

(ic), on the other hand, is predicted by my account to be necessarily either false or infelicitous (due to vacuity). Whether this prediction is right or not, I believe that it is peripheral to the topic of this paper.

${ }^{20}$ As opposed to the "Peircean" interpretation relative to $\approx$ and the epistemic one relative to $\sim$; see Burgess (1979) for a discussion of this terminology. 
The fact that (59a) is infelicitous, even though it may be (Ockham-) true, unless it receives a "settledness" interpretation, is explained in terms of pragmatic assertability conditions, which are motivated by the interaction between doxastic and metaphysical accessibility relations. For consider the result of eliminating from the listener's belief state all those (links to) indices at which the sentence is (Ockham-) false. If this update would result in a state with foreknowledge, one which "cuts across" classes of historical alternatives, the sentence is infelicitous. In order to avoid such an outcome, the listener will accommodate the presumption of decidedness if possible (i.e., if she believes that the question may be settled). Antecedents of conditionals like (59b), on this account, are exempt from this complication because they are not asserted.

This story is compelling as far as it goes. It must be dismissed, however, because a number of facts about conditionals would otherwise remain unaccounted for. To see this, consider again Crouch's example (53) from Section 7.1, repeated here as (60a).

(60) a. If I come out smiling, the interview went well.

b. If I come out smiling, the interview goes well.

c. If I come out smiling, the interview will go well.

The worlds at which the speaker comes out smiling at the future time in question are ones at which it is already (Ockham-) true at speech time that he does. Suppose (60a) is true, i.e., at all those worlds the consequent is true as well. Then the Ockhamist approach affords no explanation of the fact that the same assertion could not also be made by using (60b) or (60c). Moreover, the felicity of the Past tense in the consequent of (60a) could not be explained without further stipulations, whose nature and motivation is unclear. Even worse, the fact that among the three sentences, only (60a) has a reading which is not paraphrased as 'If it is scheduled/planned that I come out smiling...', whereas $(60 \mathrm{~b}, \mathrm{c})$ both have only that reading, remains mysterious under the Ockhamist account.

On the current account, all of these facts fall out from the assumptions about the interaction between settledness and time that are built into the model. We can assume that the truth of the antecedent will not be predetermined, so that it only becomes settled at the relevant time after the interview. The consequent therefore cannot be true at an earlier time, which explains the use of the Past tense. In $(60 \mathrm{~b}, \mathrm{c})$, on the other hand, the Present tense in the consequent requires its evaluation time, and therefore that of the antecedent as well, to be prior to the interview. Such an interpretation is not impossible, but it automatically gives rise to a "scheduling" reading 
of the antecedent, since the reference time is now later than the evaluation time. This is predicted by the non-Ockhamist truth conditions of the Present tense.

In general, the Ockhamist account offers no explanation for the fact that predictive conditionals whose antecedent refers to a future time later than that of the consequent always receive a "scheduling" interpretation. Another example to the same effect is (61).

(61) If he arrives at noon, he will take the morning train.

If (61) is to be asserted about one and the same trip, its antecedent can only have a scheduling reading.

\subsection{2 'Will'}

The antecedent of (61) must receive a scheduling reading. Antecedents expressing genuine predictions, on the other hand, would be expected to be modalized with 'will', like their unembedded counterparts. This topic deserves some brief background discussion.

As I mentioned in the introduction, the existence of conditionals whose antecedents contain 'will' with a predictive, rather than volitional interpretation, has sometimes been denied, possibly due to the influence of Jespersen's writings (Close, 1980). It is now generally accepted, however, that conditionals with predictive 'will' in the antecedent are in fact plentiful. Leech (1971) and Close (1980) discussed a number of now-standard examples (see also Dancygier, 1998; Garrett, 2001, and others). The following add to this list (emphasis added).

(62) If your nanny will need money in each of the next four years, she should predict her annual cash flow and invest so that money will be available as required to pay tuition bills and other costs. [NYT 08/07/94]

(63) If it will take 18 months to develop a product - a software package or high-tech device, for example - the carrying costs would be too high to use plastic, Scullin said.

[NYT 09/20/94]

(64) "I really said to God: 'I am willing to have an abortion. I don't think I'll ever get over it, but if I won't be a great parent for a kid to be born to under current circumstances maybe it's better if You recycle this one."

[NYT 11/30/94]

(65) If the delay will be up to 30 days, the purchaser can cancel the order and if it is more than 30 days, the order is automatically canceled unless the consumer agrees to a longer delay.

[WSJ 10/12/89] 
(66) If the worker will be running errands, ask to see driver's license and proof of insurance.

[NYT 08/08/94]

(67) If you will be installing the hardware, remember that the system will come unmonitored; hooking it up to a monitoring station can be difficult.

[NYT 08/17/94]

(68) If you will be teaching a course in summer session 2002 or next academic year in which such a service might be useful, you are most welcome to contact me (as the administrator) to be enrolled.

[university service announcement]

The antecedents in all of (62) through (68) can be paraphrased as 'If it is (or becomes) predictable that...' That 'will' implies a somewhat weaker notion of predictability than the bare present is nicely illustrated by the two conditionals in (65): The customer may cancel the order as soon as the delay is foreseeable. An automatic cancellation, on the other hand, occurs after the 30 days have in fact passed (unless the delay is "scheduled").

The above examples also exhibit what appears to be a general pattern which to my knowledge has not yet been explored in sufficient detail, and for which I am not prepared to offer an explanation either: The antecedents of (62) through (65) have stative predictates; for them 'will' is perfectly acceptable. In contrast, (66) through (68) have non-stative predicates and seem to require the progressive; without it, their antecedents would be much less acceptable unless they receive a volitional interpretation:

(66') If the worker will run errands, ask to see driver's license and proof of insurance.

(67') If you will install the hardware, remember that the system will come unmonitored...

(68') If you will teach a course in summer session 2002 or next academic year in which such a service might be useful, remember to contact me...

In discussing the combination of 'will' with the Progressive, Leech (1971) made the following suggestion, which I believe holds the key to understanding these facts (see also Palmer, 1979): ${ }^{21}$

\footnotetext{
${ }^{21}$ Wekker (1976), who claims that non-volitional 'will' does not exist in conditional antecedents because he found no instances in his 600,000-word corpus, adopts Leech's opinion about 'will/shall + Progressive' (p. 118) for other contexts.
} 
It is tempting to speculate that this usage has grown up through the need to have a way of referring to the future uncontaminated by factors of volition, plan, and intention which enter into the future meanings of 'will/shall' + Infinitive, the Present Progressive, and be going to + Infinitive.

(p. 62-63)

These insightful but purely descriptive remarks raise some interesting questions: First, what determines whether or to what extent a verb, when used in the infinitive with 'will', is subject to "contamination" by factors of volition etc.? Above I noted that the predicates of the examples in which "will + be $V$-ing' is used are non-stative, but some other, at best loosely related property - such as Agent proto-roles in their thematic structure (Dowty, 1991) — might be the real culprit. Second, why does the Progressive eliminate this reading? And finally, what about the conditional antecedent is such that if it can have a volitional interpretation, it does have it there, even when this reading is not as prominent outside of that context? ${ }^{22}$ I do not at this point have an answer to these questions.

The interpretation of such conditionals under the current proposal is illustrated with (69a), which we already encountered in (57) above. The truth conditions are paraphrased informally in (69c); I do not include the contextual variable $e_{s}$ here. $^{23}$

(69) a. If he will be alone on Christmas Day, he will let us know now.

$$
\begin{gathered}
\lambda s . \gtrless_{s}^{a}\left(\lambda j . s \sim^{a *} j \wedge\right. \\
\text { b. } \quad\left(\lambda j^{\prime} . j \sim^{b *} j^{\prime}\right) \\
\left.\left(\lambda j^{\prime} . \exists k\left[j^{\prime} \leq k \wedge \operatorname{CDAY}(k) \wedge V(\text { he be alone })(k)\right]\right)\right) \\
\quad\left(\lambda j . \exists m\left[j \leq m \wedge \operatorname{NOW}_{s}(m) \wedge V(\text { he let us know })(m)\right]\right)
\end{gathered}
$$

\footnotetext{
${ }^{22}$ The non-veridicality of the antecedents may be related to this phenomenon. Palmer (1979, p. 150) noted similar effects in questions: (ia,b) are volitional and deontic, respectively, but these connotations are absent in (ic,d).
a. Will you come to the party?
c. Will you be coming to the party?
b. Shall I come to the party?
d. Shall I be coming to the party?

Similarly, it seems, for negation:

(ii) a. I/you/she won't come to the party.

b. I/you/she won't be coming to the party.

${ }^{23}(69)$ is a variant of an example from Leech (1971) which was also used, apparently independently, by Close (1980). I changed the consequent of (69), as well as (70) below, because my analysis does not cover imperatives. Leech's version is (b), Close's is (a):

(i) a. If you will be alone on Christmas Day, let us know about it.

b. If you will be alone on Christmas Day, let us know now.
} 
c. 'I expect that he will let us know now if he (now) comes to expect to be alone on Christmas Day.' 24

Notice that the truth conditions imply that the index of evaluation $j$ lies in the interval denoted by now (the consequent states that $j$ is no later than $m$ and $m$ is in NOW). This seems to be correct for this example. This restriction is correctly predicted to disappear if 'now' is removed from the consequent, as in (70).

(70) a. If he will be alone on Christmas Day, he will let us know.

$$
\lambda s . \aleph_{a}^{a}\left(\lambda j . s \sim^{a *} j \wedge\right.
$$

b. ${ }_{k_{j}^{b}}\left(\lambda j^{\prime} \cdot j \sim^{b *} j^{\prime}\right)$ $\left(\lambda j^{\prime} . \exists k\left[j^{\prime} \leq k \wedge \operatorname{CDAY}(k) \wedge V(\right.\right.$ he be alone $\left.\left.\left.)(k)\right]\right)\right)$

$$
(\lambda j . \exists m[j \leq m \wedge V \text { (he let us know) }(m)])
$$

c. 'I expect that he will let us know if he (at some point) comes to expect to be alone on Christmas Day.'

Here the evaluation time of the antecedent may fall anywhere between speech time and Christmas Day. Notice, by the way, that this sentence comes out true even in case the subject informs the speaker after Christmas. This may appear counterintuitive at first, but it should be kept in mind that the notification would then be 'I expected to be alone on Christmas Day', rather than 'I was alone on Christmas Day'.

\subsection{Non-predictive conditionals}

In the framework developed above, the distinction between predictive and non-predictive conditionals can now be characterized in terms of temporal relations, as announced in the introduction. The semantic difference corresponds to that between the use of $R^{*}$ and $R$, respectively: The hallmark of predictive readings is that the evaluation time of their constituents is allowed to range over both present and future indices. The definition is stated in semi-formal terms in Definition 10.

\footnotetext{
${ }^{24}$ Recall that just as nothing requires the modal bases of antecedent and consequent to be the same, nothing requires them to be different either. Here they are given as $\sim^{a}$ and $\sim^{b}$, respectively, because this is the most natural interpretation. In principle, the consequent could have the speaker's modal base as well, although it requires some effort to think of a scenario in which the conditional would then be true. "His" letting "us" know would still require his expecting in addition to the speaker's.

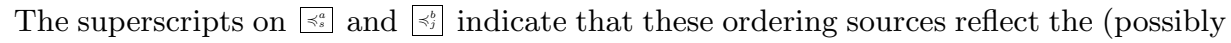
different) expectations of the respective subjects.
} 


\section{Definition 10 (Non-predictive reading)}

A conditional is interpreted non-predictively if and only if all indices at which its antecedent is evaluated are accessible from the speech index by a modal accessibility relation.

Recall that modal relations only access indices that are cotemporal with the speech index. Thus the definition captures the temporal difference that is at the bottom of the distinction.

The definition does not directly make reference to the formal difference between $R^{*}$ and $R$. I deliberately avoid such reference in order ot leave open two options for explaining how non-temporal readings come about. Such an explanation may be either semantic or pragmatic. The semantic analysis would maintain that the difference lies literally in the presence or absence of the star on the accessibility relation. The only way to account for such variability within my analysis would be to say that IF is ambiguous, its two readings corresponding to the definitions in (45) and (37) above.

The pragmatic alternative treats IF uniformly as star-inducing, attributing the restriction to speech time to the contextually given parameter $e$ that we saw in the formulas in Section (6.2). Non-predictive readings arise, under this account, whenever $e$ restricts the domain of quantification to cotemporal indices, i.e., ones that are accessible via a modal relation.

Clearly the difference in interpretation is the same under both hypotheses. I see no argument for one choice or the other, except a theory-internal one: In the spirit of Grice's "Modified Occam's Razor," ambiguity should not be postulated if the observed variation can be accounted for in other ways. I favor the pragmatic alternative with a uniform interpretation of IF as in (45).

\subsection{Epistemic conditionals}

Finally, I return once again to the question of taxonomy. Throughout this paper I distinguished between predictive and non-predictive interpretations, exemplified by $(1 \mathrm{a}, \mathrm{b})$ (repeated here as $71 \mathrm{a}, \mathrm{b})$ on their most prominent readings. There is a wide and at times confusing variety of alternative terminological proposals for this same distinction. ${ }^{25}$ Here I would like to comment on Kaufmann (2005), where (71a,b) are labeled predictive and epistemic, respectively.

\footnotetext{
${ }^{25}$ These include open vs. closed (Funk, 1985); conditional vs. hypothetical (Dudman, 1989); hypothetical vs. interactional (Garrett, 2001); doesn't-will vs. didn't-did (Bennett, 1995; Edgington, 1995); and sometimes forward-looking vs. backward-looking.
} 
(71) a. If he submits his paper to a journal, we won't include it in our book.

b. If he submitted his paper to a journal, we won't include it in our book.

The term "epistemic" corresponds to "doxastic" for present purposes. The only difference between epistemic and doxastic accessibility relations is that the former are required to be reflexive (since knowledge, unlike belief, is veridical), but this difference is irrelevant to the fact that both interpretations involve subjective beliefs.

I already argued that the distinction should not be drawn between conditionals sentences, but between their readings. With this in mind, the question arises of how close a relationship there actually is between the temporal property of "non-predictiveness" I defined above and epistemic interpretations.

The first thing to note is that nothing in my proposal implies that (71a) cannot also be interpreted with respect to an epistemic state. Indeed, such an interpretation is the most prominent one in this case, largely due to the first-person pronoun in the consequent. Thus it is not the case that predictive conditionals are necessarily non-epistemic. It is the case, however, that non-predictive conditionals tend to receive epistemic interpretations (Gibbard, 1981). This fact finds a natural explanation in the present framework.

Suppose $(71 b)$, on its natural non-predictive reading, is applied at some index $s$ to the metaphysical accessibility relation $\approx$. Since the interpretation is non-predictive, all accessible indices are cotemporal with $s$. By historical necessity, the truth value of the antecedent is constant across all these indices. As a result, if the antecedent is true, the conditional is equivalent to its consequent, and if the antecedent is false, it is either vacuously true or its truth value is undefined (depending on what is assumed about the consequences of quantifying over an empty domain). ${ }^{26}$ Due to the inclusion of the Certainty Condition in the truth conditions, this is predicted not only for the Past tense, but for the futurate Present as well.

Thus the combination of a non-predictive reading with a metaphysical modal base necessarily yields an interpretation that is somewhat degenerate. Although there is no reason to ban such readings by semantic stipulations in the truth conditions, it is good pragmatic practice to reserve non-predictive interpretations for epistemic (or doxastic) modal bases, for there the analog of the above degeneracy does not arise unless the truth value of the

\footnotetext{
${ }^{26}$ The latter case motivates Edgington's (1995) observation that there is "no ideal, objective thing to think" about a conditional, the falsehood of whose antecedent is settled.
} 
antecedent is known. ${ }^{27}$

Based on this, we can say that particular conditional sentences are associated with epistemic interpretations if, or to the extent that, their prominent interpretation is non-predictive. This is the case with $(71 \mathrm{~b})$, whose predictive interpretation involves a "past-in-the-future" reading for the antecedent that requires some context to become salient. In contrast, the predictive interpretation is the more natural one for (71a), whose non-predictive interpretation involves a "settledness" reading for the antecedent that is less prominent out of context. Thus the above argument goes some way towards explaining the prima facie plausibility of the term "epistemic" as a label for non-predictive conditionals, even though the preference for epistemic readings is really a modal side effect of their temporal interpretation.

\section{Future directions}

I have proposed a compositional treatment of simple and conditional sentences which accounts for the observed range of available readings in terms of the interplay between modal and temporal semantic ingredients. One of the main claims of the paper is that the Present tense in the antecedents of indicative conditionals receives the same interpretation that it does in isolation. I rejected earlier claims that this Present is either semantically vacuous or derived from some other underlying form.

Among the proponents of this latter view is Dancygier (1998), who calls the transformation "if-backshift" (p. 39) and relates it to what she calls "hypothetical backshift," the well-documented presence of an apparently extraneous layer of Past morphology in counterfactuals. The problem of the extra layer of Past in counterfactuals is an interesting one in the present context. While some authors have sought to incoporate its temporal meaning into the semantics of counterfactuals (Tedeschi, 1981; Dahl, 1997, and many philosophers), others, including Dancygier, take it to be devoid of temporal significance (see also Palmer, 1974; Heim, 1992; Iatridou, 2000;

\footnotetext{
${ }^{27}$ This is part of a larger pattern in the interaction between modal and temporal dimensions in the interpretation of modals. For instance, Condoravdi (2002) explains the observation that (ia,b) can only have epistemic interpretations, whereas (ic) is not so constrained, in terms of the same interaction between epistemic and metaphysical modal bases.

(i) a. He may be sick (now).

b. He may have been sick (last week).

c. He may get sick.
} 
Ippolito, 2003). Dancygier suggests that both types of backshift involve a non-temporal reading of otherwise temporal expressions, specifying this reading along the lines of James (1982) and Fleischman (1989). I disagree with this treatment of indicatives, but have said nothing about counterfactuals. If my proposal has succeeded in accounting for "if-backshift" while preserving the temporal interpretation of the Present, the question arises what it would take to extend it to counterfactuals. I leave this question for future research.

Another open question concerns modalities other than those I dealt with in this paper. I mentioned in Footnote 6 that both doxastic and objective modals are subsumed under the linguistic category of "epistemic" modality, as opposed to "root" modality. There is a structural difference between these two classes that is as-yet not well understood, but it appears that root modals tend to be more deeply buried in the derivation tree (hence the label can be a bit misleading). A hypothesis I consider worth exploring is that root modals are generally embedded in the nuclear scope of an outer epistemic modal of the kind I have discussed here. I leave this question, along with the task of exploring its implications for the analysis of conditionals, for future work.

\section{References}

Abusch, D. 1997. Sequence of tense and temporal de re. Linguistics and Philosophy, 20:1-50.

Abusch, D. 1998. Generalizing tense semantics for future contexts. In Rothstein, S., editor, Events and Grammar, volume 70 of Studies in Linguistics and Philosophy, pages 13-33. Kluwer.

Athanasiadou, A. and R. Dirven, editors. 1997. On Conditionals Again, volume 143 of Amsterdam Studies in the Theory and History of Linguistic Science. John Benjamins.

Bennett, J. 1995. Classifying conditionals: The traditional way is right. Mind, 104(414):332-354.

Bennett, M. and B. Partee. 1978. Toward the logic of tense and aspect in English. Reproduced by the Indiana University Linguistics Club.

Brennan, V. 1993. Root and Epistemic Modal Auxiliary Verbs. PhD thesis, University of Massachusetts, Amherst.

Burgess, J. P. 1979. Logic and time. The Journal of Symbolic Logic, 44(4): $566-582$.

Close, R. 1980. Will in if-clauses. In Greenbaum, S., G. Leech, and 
J. Svartvik, editors, Studies in English Linguistics for Randolph Quirk, pages 100-109. Longman.

Comrie, B. 1982. Future time reference in the conditional protasis. Australian Journal of Linguistics, pages 143-152.

Comrie, B. 1985. Tense. Cambridge University Press.

Condoravdi, C. 2002. Temporal interpretation of modals: Modals for the present and modals for the past. In Beaver, D. I., L. Casillas, B. Clark, and S. Kaufmann, editors, The Construction of Meaning, pages 59-88. CSLI Publications.

Condoravdi, C. 2003. Moods and modalities for will and would. Handout from the 14th Amsterdam Colloquium.

Crouch, R. 1993. The Temporal Properties of English Conditionals and Modals. PhD thesis, University of Cambridge.

Dahl, O. 1997. The relation between past time reference and counterfactuality: A new look. In Athanasiadou and Dirven (1997), pages 97-112.

Dancygier, B. 1998. Conditionals and Prediction. Cambridge University Press.

Declerck, R. and S. Reed. 2001. Conditionals: A Comprehensive Empirical Analysis. Number 37 in Topics in English Linguistics. Mouton de Gruyter.

Dowty, D. 1977. Towards a semantic analysis of verb aspect and the English 'imperfective' progressive. Linguistics and Philosophy, 1:45-77.

Dowty, D. 1979. Word Meaning and Montague Grammar, volume 7 of Studies in Linguistics and Philosophy. Reidel.

Dowty, D. 1991. Thematic proto-roles and argument selection. Language, 67:547-619.

Dudman, V. H. 1984. Parsing 'If'-sentences. Analysis, 44(4):145-153.

Dudman, V. H. 1989. Vive la Révolution! Mind, 98(392):591-603.

Edgington, D. 1995. On conditionals. Mind, 104(414):235-329.

Edgington, D. 1997. Commentary. In Woods (1997), pages 97-137. Clarendon Press.

Fagin, R., J. Y. Halpern, Y. Moses, and M. Y. Vardi. 1995. Reasoning about Knowledge. MIT Press.

Fernando, T. 2003. Reichenbach's $E, R$, and $S$ in a finite-state setting. http://www.cs.tcd.ie/Tim.Fernando/wien.pdf. Last checked: January, 2004 .

von Fintel, K. 1994. Restrictions on Quantifier Domains. PhD thesis, University of Massachusetts.

Fleischman, S. 1989. Temporal distance: A basic linguistic metaphor. Studies in Language, 13(1):1-50.

van Fraassen, B. C. 1980. Review of Brian Ellis, "Rational Belief Systems". 
Canadian Journal of Philosophy, 10:457-511.

van Fraassen, B. C. 1981. A temporal framework for conditionals and chance. In Harper et al. (1981), pages 323-340.

Frank, A. 1996. Context Dependence in Modal Constructions. PhD thesis, Institut für maschinelle Sprachverarbeitung (Stuttgart).

Funk, W.-P. 1985. On a semantic typology of conditional sentences. Folia Linguistica, 19(3/4):365-414.

Gabbay, D. and F. Guenthner, editors. 1984. Extensions of Classical Logic, volume 2 of Handbook of Philosophical Logic. D. Reidel.

Garrett, E. J. 2001. Evidentiality and Assertion in Tibetan. $\mathrm{PhD}$ thesis, University of California.

Gennari, S. 2003. Tense meanings and temporal interpretation. Journal of Semantics, 20:35-71.

Gibbard, A. 1981. Two recent theories of conditionals. In Harper et al. (1981), pages 211-247.

Goodman, F. 1973. On the semantics of futurate sentences. In Mostly Syntax and Semantics, number 16 in Working Papers in Linguistics, pages 76-89. Department of Linguistics, The Ohio State University.

Halpern, J. Y. 1997. Defining relative likelihood in partially-ordered preferential structures. Journal of Artificial Intelligence Research, 7:1-27.

Halpern, J. Y. 2003. Reasoning about Uncertainty. MIT Press.

Harper, W. L., R. Stalnaker, and G. Pearce, editors. 1981. Ifs: Conditionals, Belief, Decision, Chance, and Time. Reidel.

Heim, I. 1992. Presupposition projection and the semantics attitude verbs. Journal of Semantics, 9:183-221.

Hofmann, T. R. 1976. Past tense replacement and the modal system. In McCawley, J. D., editor, Notes from the Linguistic Underground, volume 7 of Syntax and Semantics, pages 85-100. Academic Press.

Hornstein, N. 1990. As Time Goes By: Tense and Universal Grammar. MIT Press.

Huddleston, R. and G. K. Pullum. 2002. The Cambridge Grammar of the English Language. Cambridge University Press.

Iatridou, S. 2000. The grammatical ingredients of counterfactuality. Linguistic Inquiry, 31(2):231-270.

Ippolito, M. 2003. Presuppositions and implicatures in couterfactuals. Journal of Semantics, 11:145-186.

Jackendoff, R. 1972. Semantic Interpretation in Generative Grammar. MIT Press.

James, D. 1982. Past tense and the hypothetical: A cross-linguistic study. Studies in Language, 6(3):375-403. 
Joos, M. 1964. The English Verb. University of Wisconsin Press.

Kamp, H. and U. Reyle. 1993. From Discourse to Logic. Kluwer.

Kaufmann, S. 2002. The presumption of settledness. To appear in Proceedings of $C L S 38$.

Kaufmann, S. 2005. Conditional predictions: A probabilistic account. Linguistics and Philosophy. To appear.

Kratzer, A. 1979. Conditional necessity and possibility. In Egli, U., R. Bäuerle, and A. von Stechow, editors, Semantics from Different Points of View, pages 117-147. Springer.

Kratzer, A. 1981. The notional category of modality. In Eikmeyer, J. and H. Riesner, editors, Words, Worlds, and Contexts, pages 38-74. Walter de Gruyter.

Kratzer, A. 1991. Modality. In von Stechow, A. and D. Wunderlich, editors, Semantik: Ein internationales Handbuch der zeitgenössischen Forschung. [=Semantics], pages 639-650. de Gruyter.

Lakoff, G. 1971. Presupposition and relative well-formedness. In Steinberg, D. and L. Jakobovits, editors, Semantics, pages 329-340. Cambridge University Press.

Leech, G. 1971. Meaning and the English Verb. Longman.

Lewis, D. 1986. Postscript to "Probabilities of conditionals and conditional probabilities". In Philosophical Papers, volume 2, pages 152-156. Oxford University Press.

McCawley, J. D. 1971. Tense and time reference in English. In Fillmore, C. and D. Langedoen, editors, Studies in Linguistic Semantics. Holt.

Mellor, D. H., editor. 1990. Philosophical Papers: F. P. Ramsey. Cambridge University Press.

Palmer, F. R. 1974. The English Verb. Longman.

Palmer, F. R. 1979. Modality and the English Modals. Longman.

Portner, P. 2003. The (temporal) semantics and (modal) pragmatics of the perfect. Linguistics and Philosophy, 26:459-510.

Prior, A. 1967. Past, Present and Future. Oxford University Press.

Quirk, R., S. Greenbaum, G. Leech, and J. Svartvik. 1985. A Comprehensive Grammar of the English Language. Longman.

Ramsey, F. P. 1929. General propositions and causality. Printed in Mellor (1990), pages $145-163$.

Smith, C. S. 1991. The Parameter of Aspect, volume 43 of Studies in Linguistics and Philosophy. Kluwer.

Stalnaker, R. 1968. A theory of conditionals. In Studies in Logical Theory, American Philosophical Quarterly, Monograph: 2, pages 98-112. Blackwell. 
Stalnaker, R. 1975. Indicative conditionals. Philosophia, 5:269-286.

Stalnaker, R. 2002. Common ground. Linguistics and Philosophy, 25:701721.

Steedman, M. 2002. The productions of time. Unpublished ms., Version 4.1.

Stone, M. 1994. The reference argument of epistemic Must. In Proceedings of IWCS 1, pages 181-190.

Tedeschi, P. 1981. Some evidence for a branching-futures semantic model. In Tedeschi, P. and A. Zaenen, editors, Tense and Aspect, volume 14 of Syntax and Semantics, pages 239-270. Academic Press.

Thomason, R. H. 1970. Indeterminist time and truth value gaps. Theoria, $36: 264-281$.

Thomason, R. H. 1984. Combinations of tense and modality. In Gabbay and Guenthner (1984), pages 135-165.

Thomason, R. H. and A. Gupta. 1981. A theory of conditionals in the context of branching time. In Harper et al. (1981), pages 299-322.

Traugott, E. C., A. ter Meulen, J. Snitzer Reilly, and C. A. Ferguson, editors. 1986. On Conditionals. Cambridge University Press.

Veltman, F. 1985. Logics for Conditionals. PhD thesis, University of Amsterdam.

Veltman, F. 1986. Data semantics and the pragmatics of indicative conditionals. In Traugott et al. (1986), pages 147-168.

Vetter, D. 1973. Someone solves this problem tomorrow. Linguistic Inquiry, 4(1):104-108.

Wekker, H. C. 1976. The Expression of Future Time in Contemporary British English. Number 28 in North-Holland Linguistic Series. NorthHolland.

Westmoreland, R. R. 1995. Epistemic must as evidential. In Dekker, P. and M. Stokhof, editors, Proceedings of the 10th Amsterdam Colloquium, volume 3, pages 683-702, Amsterdam. ILLC.

Woods, M. 1997. Conditionals. Clarendon Press.

Zandvoort, R. W. 1965. A Handbook of English Grammar. Longmans.

Zvolenszky, Z. 2002. Is a possible-worlds semantics of modality possible? A problem for Kratzer's semantics. In Jackson, B., editor, Proceedings of SALT XII. 